\title{
Effectiveness of Traditional Strength vs. Power Training on Muscle Strength, Power and Speed with Youth: A Systematic Review and Meta-Analysis
}

David G. Behm ${ }^{1 *}$, James D. Young ${ }^{1}$, Joseph H. D. Whitten ${ }^{1}$, Jonathan C. Reid ${ }^{1}$, Patrick J. Quigley ${ }^{1}$, Jonathan Low ${ }^{1}$, Yimeng Li ${ }^{1}$, Camila D. Lima ${ }^{1}$, Daniel D. Hodgson ${ }^{1}$, Anis Chaouachi ${ }^{2,3}$, Olaf Prieske ${ }^{4}$ and Urs Granacher ${ }^{4}$

\footnotetext{
${ }^{1}$ School of Human Kinetics and Recreation, Memorial University of Newfoundland, St. John's, NL, Canada, ${ }^{2}$ Tunisian Research Laboratory "Sport Performance Optimisation", National Center of Medicine and Science in Sports, Tunis, Tunisia, ${ }^{3}$ Sports Performance Research Institute New Zealand, Auckland University of Technology, Auckland, New Zealand, ${ }^{4}$ Division of Training and Movement Sciences, Research Focus Cognition Sciences, University of Potsdam, Potsdam, Germany
}

\section{OPEN ACCESS}

Edited by:

Kimberly Huey,

Drake University, United States

Reviewed by:

Brian H. Dalton,

University of British Columbia

Okanagan, Canada

Shane A. Phillips,

University of Illinois at Chicago,

United States

*Correspondence:

David G. Behm

dbehm@mun.ca

Specialty section:

This article was submitted to

Exercise Physiology,

a section of the journal

Frontiers in Physiology

Received: 02 April 2017 Accepted: 01 June 2017

Published: 30 June 2017

Citation:

Behm DG, Young JD, Whitten JHD,

Reid JC, Quigley PJ, Low J, Li Y, Lima $C D$, Hodgson DD, Chaouachi A,

Prieske O and Granacher U (2017)

Effectiveness of Traditional Strength

vs. Power Training on Muscle

Strength, Power and Speed with

Youth: A Systematic Review and

Meta-Analysis. Front. Physiol. 8:423.

doi: 10.3389/fphys.2017.00423
Numerous national associations and multiple reviews have documented the safety and efficacy of strength training for children and adolescents. The literature highlights the significant training-induced increases in strength associated with youth strength training. However, the effectiveness of youth strength training programs to improve power measures is not as clear. This discrepancy may be related to training and testing specificity. Most prior youth strength training programs emphasized lower intensity resistance with relatively slow movements. Since power activities typically involve higher intensity, explosive-like contractions with higher angular velocities (e.g., plyometrics), there is a conflict between the training medium and testing measures. This meta-analysis compared strength (e.g., training with resistance or body mass) and power training programs (e.g., plyometric training) on proxies of muscle strength, power, and speed. A systematic literature search using a Boolean Search Strategy was conducted in the electronic databases PubMed, SPORT Discus, Web of Science, and Google Scholar and revealed 652 hits. After perusal of title, abstract, and full text, 107 studies were eligible for inclusion in this systematic review and meta-analysis. The meta-analysis showed small to moderate magnitude changes for training specificity with jump measures. In other words, power training was more effective than strength training for improving youth jump height. For sprint measures, strength training was more effective than power training with youth. Furthermore, strength training exhibited consistently large magnitude changes to lower body strength measures, which contrasted with the generally trivial, small and moderate magnitude training improvements of power training upon lower body strength, sprint and jump measures, respectively. Maturity related inadequacies in eccentric strength and balance might influence the lack of training specificity with the unilateral landings and propulsions associated with sprinting. Based on this meta-analysis, strength training should be incorporated prior to power training in order to establish an adequate foundation of strength for power training activities.

Keywords: children, boys, girls, plyometric training, resistance training 


\section{INTRODUCTION}

In contrast to the prior myths of health concerns regarding resistance training (RT) for children (Rians et al., 1987; Blimkie, 1992, 1993; Faigenbaum and Kang, 2005), the contemporary research emphasizes the beneficial effect of youth RT for health, strength, and athletic performance (Sale, 1989; Webb, 1990; Faigenbaum et al., 1996, 2009; Falk and Tenenbaum, 1996; Payne et al., 1997; Golan et al., 1998; Hass et al., 2001; McNeely and Armstrong, 2002; Falk and Eliakim, 2003; American College of Sports Medicine, 2006; Faigenbaum, 2006; Malina, 2006; Behm et al., 2008; Granacher et al., 2016). With a properly implemented youth RT program, muscular strength and endurance can increase significantly beyond normal growth and maturation (Pfeiffer and Francis, 1986; Weltman et al., 1986; Sailors and Berg, 1987; Blimkie, 1989; Ramsay et al., 1990; Faigenbaum et al., 1996, 1999, 2001, 2002). Falk and Tenenbaum (1996) conducted a meta-analysis and reported RT-induced strength increases of $13-30 \%$ in pre-adolescent children following RT programs of 820 weeks. The Canadian Society for Exercise Physiology (CSEP) position stand (Behm et al., 2008) indicated that the literature provided a clear positive effect for improving muscle strength. In contrast, there were far fewer RT studies that measured power capacities, which only provided small effects for adolescents and unclear effects of RT on improving power for children (Weltman et al., 1986; Faigenbaum et al., 1993, 2002, 2007b, 1996; Lillegard et al., 1997; Christou et al., 2006; Granacher et al., 2016).

The small or unclear effects of traditional strength/RT on measures of power in children in the Behm et al. (2008) review could be attributed to the few studies published up to that year that monitored proxies of power. The recent Granacher et al. (2016) review cited only three studies with girls as participants compared to 27 studies with boys but still reported small to barely moderate effects of RT on muscular power. Other factors contributing to smaller effects of traditional strength/RT on measures of power in children could be the lack of training mode specificity (Sale and MacDougall, 1981; Behm and Sale, 1993; Behm, 1995) or perhaps maturation-related physiological limitations upon power training adaptations in children. The typical strength RT protocol for children involves training 23 times per week (Malina, 2006), with moderate loads (e.g., 50-60\% of 1RM) and higher repetitions (e.g., 15-20 reps) (Faigenbaum et al., 1996, 2009; Lillegard et al., 1997; Christou et al., 2006; Faigenbaum, 2006; Benson et al., 2007; Behm et al., 2008). According to the concept of training specificity, an effective transfer of training adaptations occurs when the training matches the task (e.g., testing, competition) (Sale and MacDougall, 1981; Behm and Sale, 1993; Behm, 1995). Since high power outputs involve explosive contractions with forces exerted at higher velocities, RT programs using low to moderate loads at slower velocities would not match power characteristics. However, recently there are a number of publications that have implemented power training programs (e.g., plyometric training) for children that would adhere to the training specificity principle. Plyometric exercises involve jumping, hopping, and bounding exercises and throws that are performed quickly and explosively (Behm, 1993; Behm et al., 2008; Cappa and
Behm, 2011, 2013). With plyometric training adaptations, the neuromuscular system is conditioned to react more rapidly to the stretch-shortening cycle (SSC). Plyometric training can be safe and may improve a child's ability to increase movement speed and power production provided that appropriate training and guidelines are followed (Brown et al., 1986; Diallo et al., 2001; Matavulj et al., 2001; Lephart et al., 2005; Marginson et al., 2005; Kotzamanidis, 2006; Behm et al., 2008). Johnson et al. (2011) published a meta-analysis that only included seven studies that they judged to be of low quality. They suggested that plyometric training had a large positive effect on running, jumping, kicking distance, balance, and agility with children. Hence, further analysis is needed with a greater number of power training studies involving children and/or adolescents.

While many power activities involve shorter duration, higher intensity, explosive type contractions (anaerobic emphasis), children are reported to possess reduced anaerobic capacities (Behm et al., 2008; Murphy et al., 2014) with a lower reliance on glycolysis (Ratel et al., 2006, 2015), and lower power outputs (Falk and Dotan, 2006) compared to adults. In the recently published scoping review (Granacher et al., 2016), Granacher and colleagues were able to show small effect sizes following RT on measures of power in child athletes and moderate effect sizes in adolescent athletes. However, these authors looked at general RT effects only and did not differentiate between strength and power training programs. Moreover, only studies conducted with youth athletes were analyzed.

Thus, it was the objective of this systematic review and meta-analysis to investigate whether there are different effects following strength vs. power training on measures of muscle strength, power, and speed in trained and untrained children and adolescents. It is hypothesized that in accordance with the concept of training specificity, power training programs will provide more substantial improvements in power and speed measures than traditional strength programs with youth. Furthermore, since trained individuals would have a greater foundation of strength, we expected greater power training related effects in trained compared to untrained youth.

\section{METHODS}

\section{Search Strategy and Inclusion/Exclusion Criteria}

This review included randomized controlled trials and controlled trials that implemented either traditional strength/resistance training or power training in youth. A literature search was performed by four co-authors separately and independently using PubMed, SPORT Discus, Web of Science, and Google Scholar databases. The topic was systematically searched using a Boolean search strategy with the operators AND, OR, NOT and a combination of the following keywords: ("strength training" OR "resistance training" OR "weight training" OR "power training" OR "plyometric training" OR "complex training" OR "compound training" OR "weight-bearing exercise") AND (child OR children OR adolescent OR adolescents OR youth OR puberty OR prepuberal* OR kids OR kid OR teen* OR girl* OR boy OR boys) 
NOT (patient OR patients OR adults OR adult OR man OR men OR woman OR women). All references from the selected articles were also crosschecked manually by the authors to identify relevant studies that might have been missed in the systematic search and to eliminate duplicates.

\section{Inclusion Criteria (Study Selection)}

Studies investigating traditional strength/resistance training or power training in youth were included in the review if they fulfilled the following selection criteria: the study (1) was a randomized controlled trial or a controlled trial; (2) measured pre- and post-training strength [e.g., maximal loads (i.e., 1 repetition maximum: 1RM) or forces with squats, leg extension or flexion, isokinetic maximal measures], power-related [e.g., countermovement jump (CMJ), horizontal or standing long jump (SLJ)] or speed-related (e.g., 10-m sprint time) dependent variables; (3) training duration was greater than 4 weeks; (4) used healthy, untrained (i.e., physical education classes and/or no specific sport) or trained (i.e., youth athletes from different sports) youth participants under the age of 18 years; (5) was written in English and published prior to January 2017; and (6) was published in a peer-reviewed journal (abstracts and unpublished studies were excluded). Studies were excluded if precise means and standard deviations, or effect sizes were not available or if the training study combined both strength and power exercises. Our initial search resulted in 652 applicable studies (see flow chart: Figure 1).

\section{Statistical Analyses}

For statistical analyses, within-subject standardized mean differences of the each intervention group were calculated $[\mathrm{SMD}=$ (mean post-value intervention group-mean pre-value intervention group)/pooled standard deviation]. Subsequently, SMDs were adjusted for the respective sample size by using the term (1-(3/(4N-9))) (Hedges, 1985). Meta-analytic comparisons were computed using Review Manager software V.5.3.4 (Copenhagen: The Nordic Cochrane Centre, The Cochrane Collaboration, 2008). Included studies were weighted according to the magnitude of the respective standard error using a random-effects model. A random effect model was used because the relative weight assigned to each of the studies has less impact on computed combined effect size. In other words, in the fixed effect model, one or two studies with relatively high weight can shift the combined effect size and associated confidence intervals in one particular direction, whereas in a random effect model this issue is moderated.

Further, we used Review Manager for subgroup analyses: computing a weight for each subgroup (e.g., trained vs. untrained), aggregating SMD values of specific subgroups, and comparing subgroup effect sizes with respect to differences in intervention effects across subgroups. To improve readability, we reported positive SMDs if superiority of post values compared with pre-values was found. Heterogeneity was assessed using $\mathrm{I}^{2}$ and $\chi^{2}$ statistics. SMDs were calculated to evaluate the magnitude of the difference between traditional resistance and plyometric training according to the criterion of 0.80 large; 0.50 medium and 0.20 small (Cohen, 1988).

\section{RESULTS}

\section{Training Program Prescriptions}

The descriptive statistics for the strength and power training program prescriptions are illustrated in Table 1. There were $28.5 \%$ more strength training studies within the literature review likely due to the fact that power training experiments for children began more recently (power: 1999 vs. strength: 1986 with one pediatric strength study published in 1958). Strength training studies on average had younger participants ( $\sim 12$ vs. 13 years), $45.2 \%$ longer duration training programs ( $\sim 8$ vs. 12 weeks) and implemented approximately 1 less exercise per training session. There were substantially more untrained or physical education student participants in the strength studies (i.e., strength studies with physical education and untrained: 31 vs. power studies with physical education and untrained: 6 with soccer athletes used most often (strength: 9 studies and power: 20 studies). Details of all studies in the review are depicted in Tables 2 A,B.

\section{Muscle Power (Jump) Measures}

Table 3 shows that power (plyometric) training studies provided higher magnitude changes in jump performance than strength training studies. In terms of general descriptors, power training studies exceeded strength training studies with trained (moderate vs. small), untrained (large vs. moderate)(Figures 2, 4) and adolescent (moderate vs. small) populations (Figures 3, 5). For the overall or general results (Figures 2, 4) as well as with children (Figures 3, 5), the descriptive classifications were the same (moderate magnitude improvements), although the precise SMDs values were higher with power training. When comparing specific populations (power and strength training combined), untrained individuals (moderate to large magnitude) experienced greater jump height gains than trained participants (small to moderate). Similarly, with training groups combined, children experienced larger jump height gains than adolescents, although the descriptive classification only differed with strength training (moderate vs. small), but not power training.

\section{Sprint Speed Measures}

In contrast to power (jump) results, strength training studies tended to provide better sprint time results than power training (Table 2). However, it was only in the children and adolescent strength vs. power training comparison where the descriptive classifications for strength training exceeded power training with moderate vs. small and small vs. trivial classifications, respectively (Figures 7, 9). In contrast, power training (only 3 measures) provided a greater magnitude change than strength training (30 measures) with untrained populations demonstrating a large vs. moderate improvement in sprint time (Figures 6, 8). Again, similar to power (jump) measures, untrained and child populations had greater magnitudes and descriptors than trained and adolescents respectively for both strength and power training.

\section{Muscle Strength Measures}

There were very few power training studies that measured lower body strength with no studies that utilized children or differentiated between trained and untrained individuals 


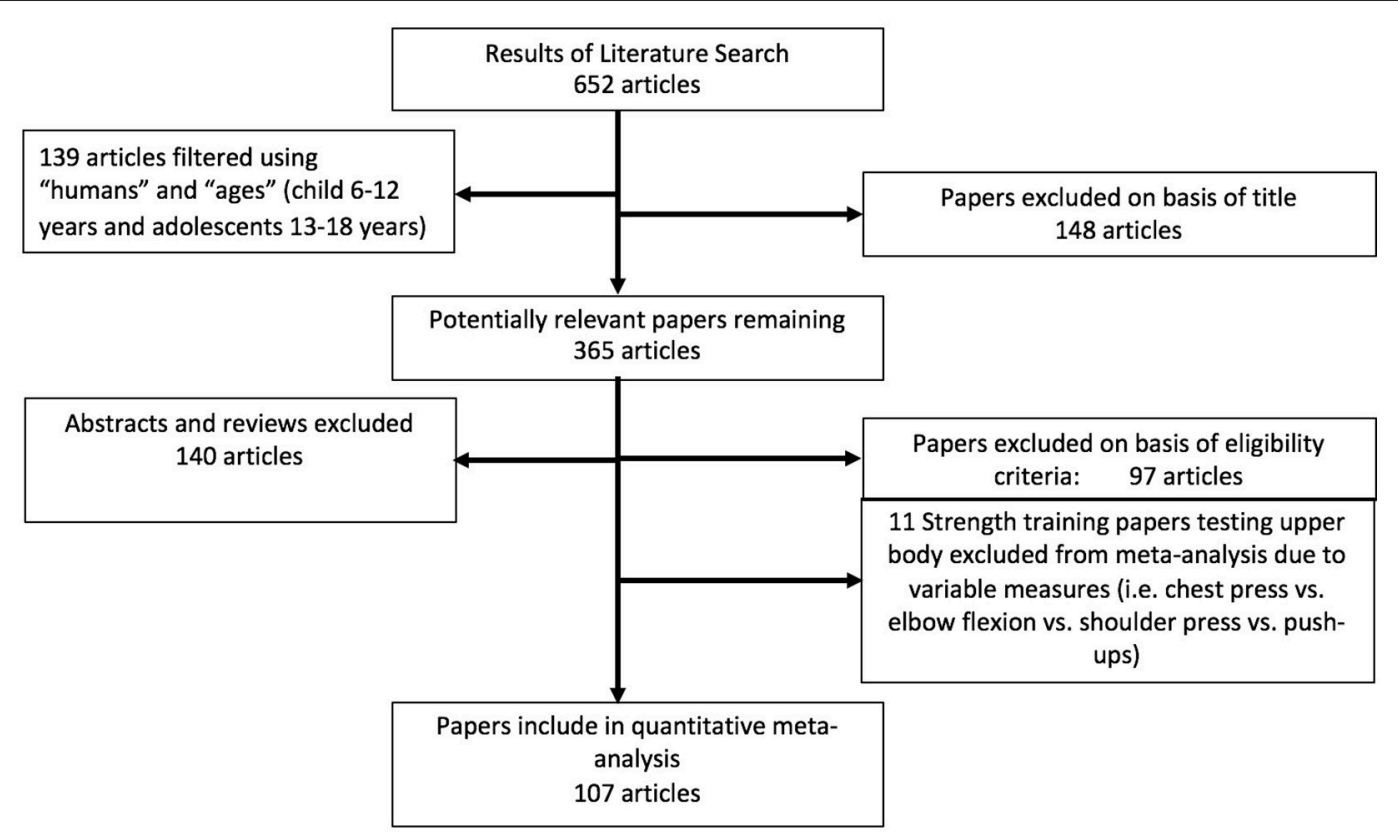

FIGURE 1 | Flow chart illustrating the different phases of the search and study selection.

TABLE 1 | Training participants and program characteristics.

\begin{tabular}{|c|c|c|c|c|c|c|c|c|c|}
\hline $\begin{array}{l}\text { No. of } \\
\text { Studies }\end{array}$ & $\begin{array}{c}\text { No. of } \\
\text { studies with } \\
\text { all male } \\
\text { subjects }\end{array}$ & $\begin{array}{l}\text { No. of studies } \\
\text { with all female } \\
\text { subjects }\end{array}$ & $\begin{array}{l}\text { No. of studies } \\
\text { with male and } \\
\text { female subjects }\end{array}$ & Age (years) & $\begin{array}{c}\text { Training frequency } \\
\text { (sessions } \\
\text { per week) }\end{array}$ & $\begin{array}{l}\text { Training } \\
\text { Weeks }\end{array}$ & Sets & No. of Exerc. & Reps \\
\hline $\begin{array}{l}\text { Strength } 63 \\
(1958, \text { and } \\
1986-2016)\end{array}$ & 32 & 1 & 30 & $12.37 \pm 0.73$ & $2.2 \pm 0.52$ & $12.45 \pm 14.04$ & $2.76 \pm 1.16$ & $6.15 \pm 2.94$ & $9.83 \pm 4.08$ \\
\hline $\begin{array}{l}\text { Power } 52 \\
(1999-2016)\end{array}$ & 38 & 11 & 3 & $13.5 \pm 0.86$ & $2.27 \pm 0.58$ & $8.57 \pm 4.34$ & $2.15 \pm 1.81$ & $7.69 \pm 4.94$ & $9.94 \pm 7.91$ \\
\hline
\end{tabular}

reps, repetitions; Exerc, exercises. Values provided in first four columns are sums, whereas the last six columns are means and standard deviations.

Number of studies: Strength participants: Physical Education: 15 studies, Untrained: 16 studies.

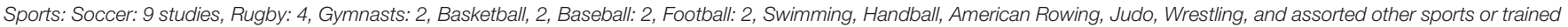
states.

Power participants: Physical Education: 3 studies, Untrained: 3 studies.

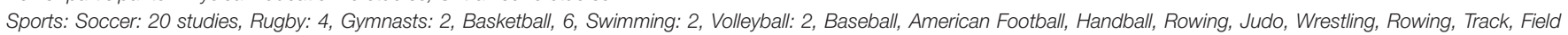
hockey, Tennis, and assorted other sports or trained states.

(Figure 10). The 4 power training measures within our review used adolescents with only a trivial magnitude improvement compared to large magnitude improvements in all categories $(0.88-1.35)$ with the 45 strength training measures (Figures 11, 12).

\section{DISCUSSION}

This is the first systematic review and meta-analysis that compared the effects of strength vs. power training on measures of muscle strength, power, and speed in trained and untrained youth. The most pertinent findings of the present study were the tendencies for training specificity with power measures (power training more effective than strength training), but a lack of training specificity with sprint measures (strength training more effective than power training) with youth. Thirdly, strength training exhibited uniformly large magnitude changes to lower body strength measures, which contrasted with the generally trivial, small and moderate magnitude training improvements of power training upon lower body strength, sprint and jump power measures, respectively. Furthermore, untrained youth displayed more substantial improvements in jump and sprint measures with both power and strength training compared to trained youth.

The greater magnitude improvements in power measures with power vs. strength training corresponds with the training specificity principle (Sale and MacDougall, 1981; Behm, 1988, 1995; Behm and Sale, 1993). Training specificity dictates that training adaptations are greater when the training mode, 


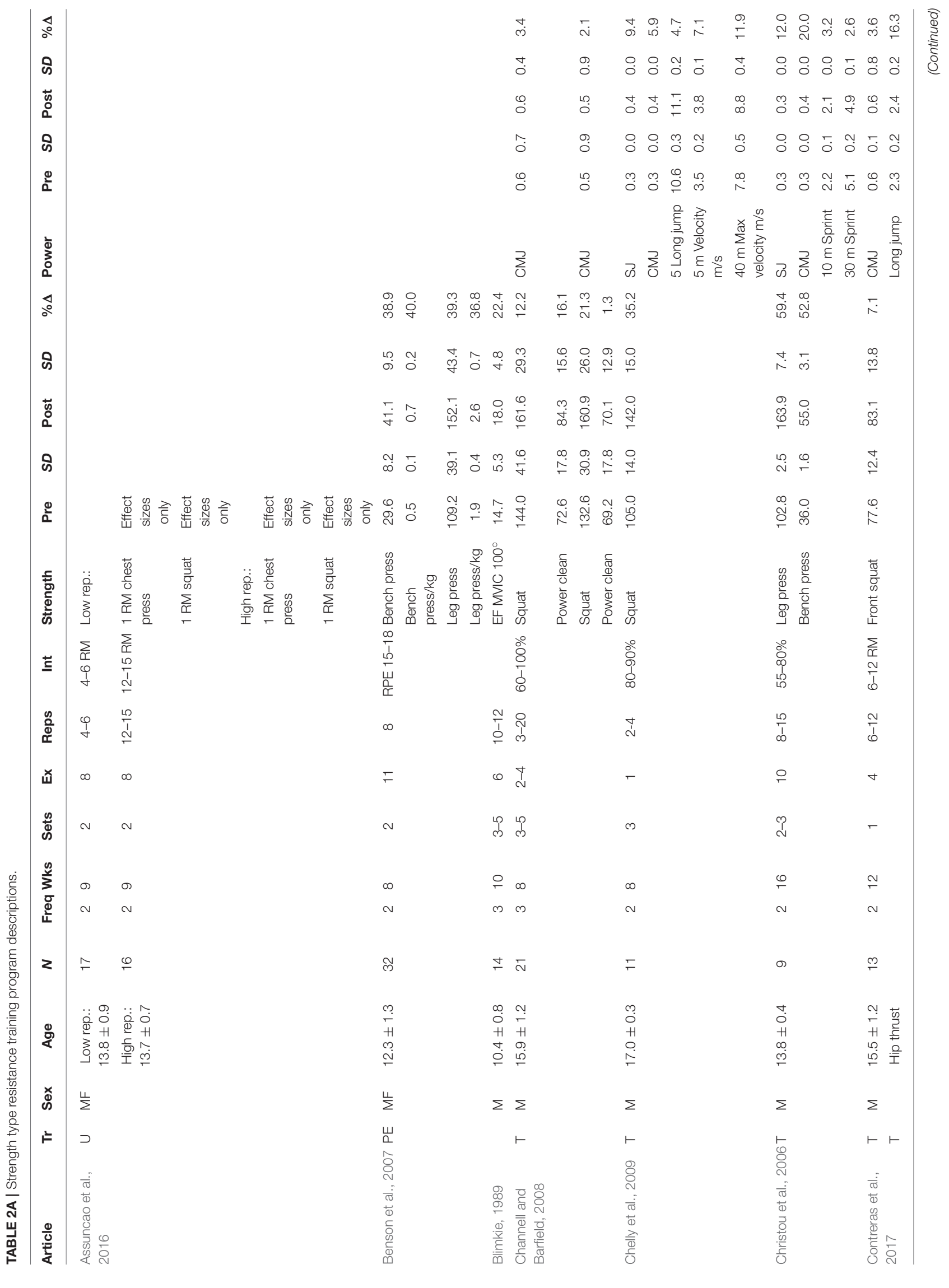




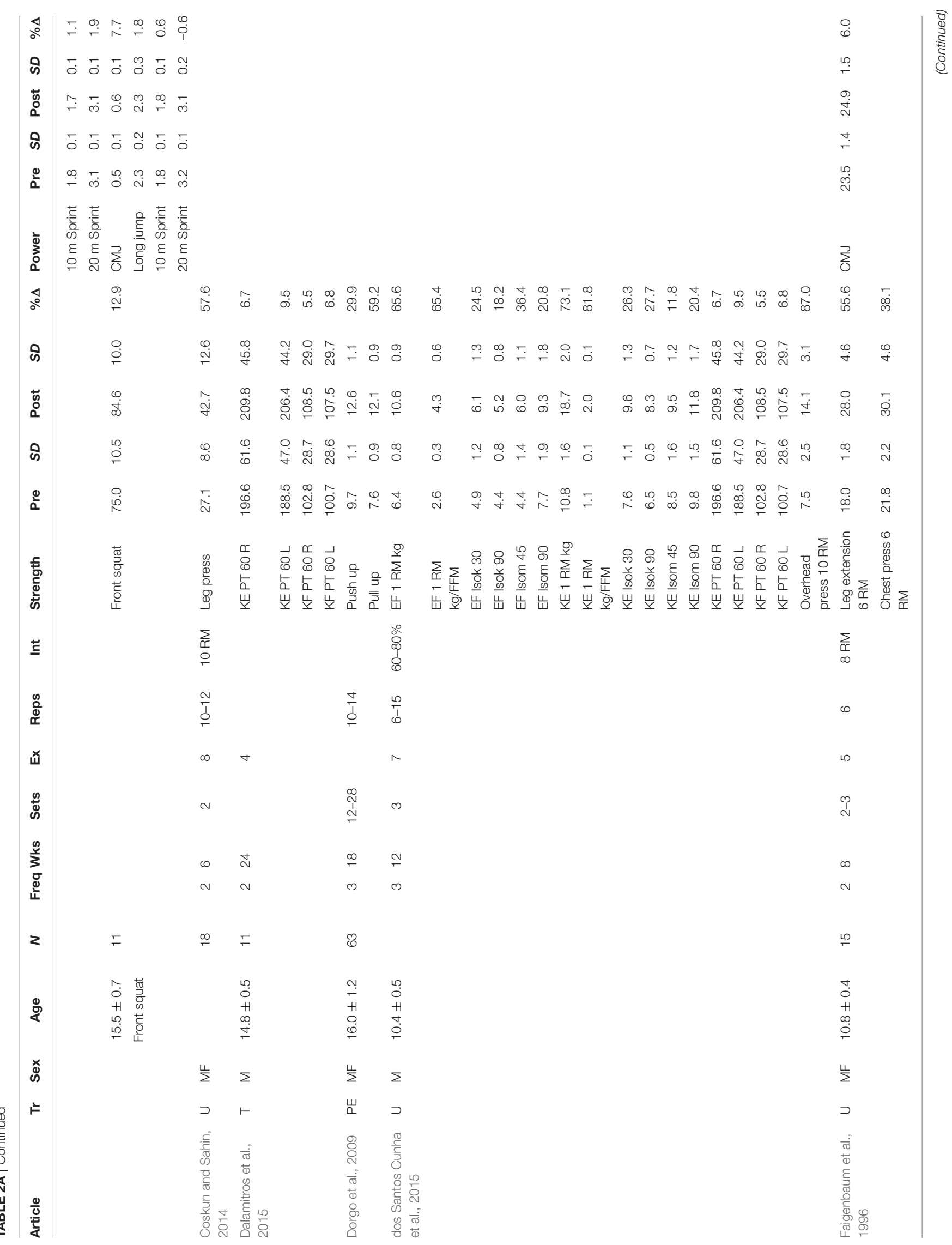




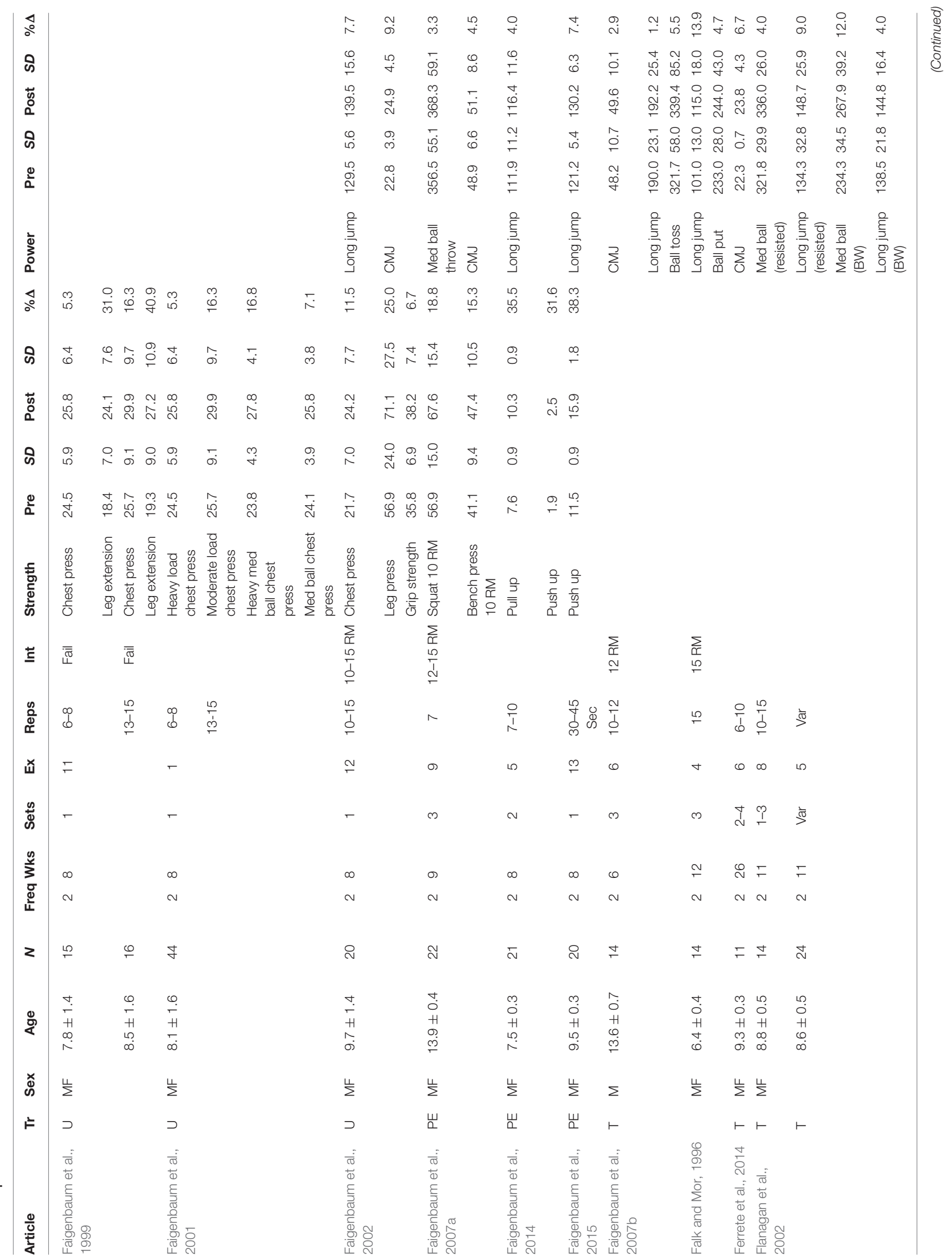


Berm et al.

Youth Strength vs. Power Training

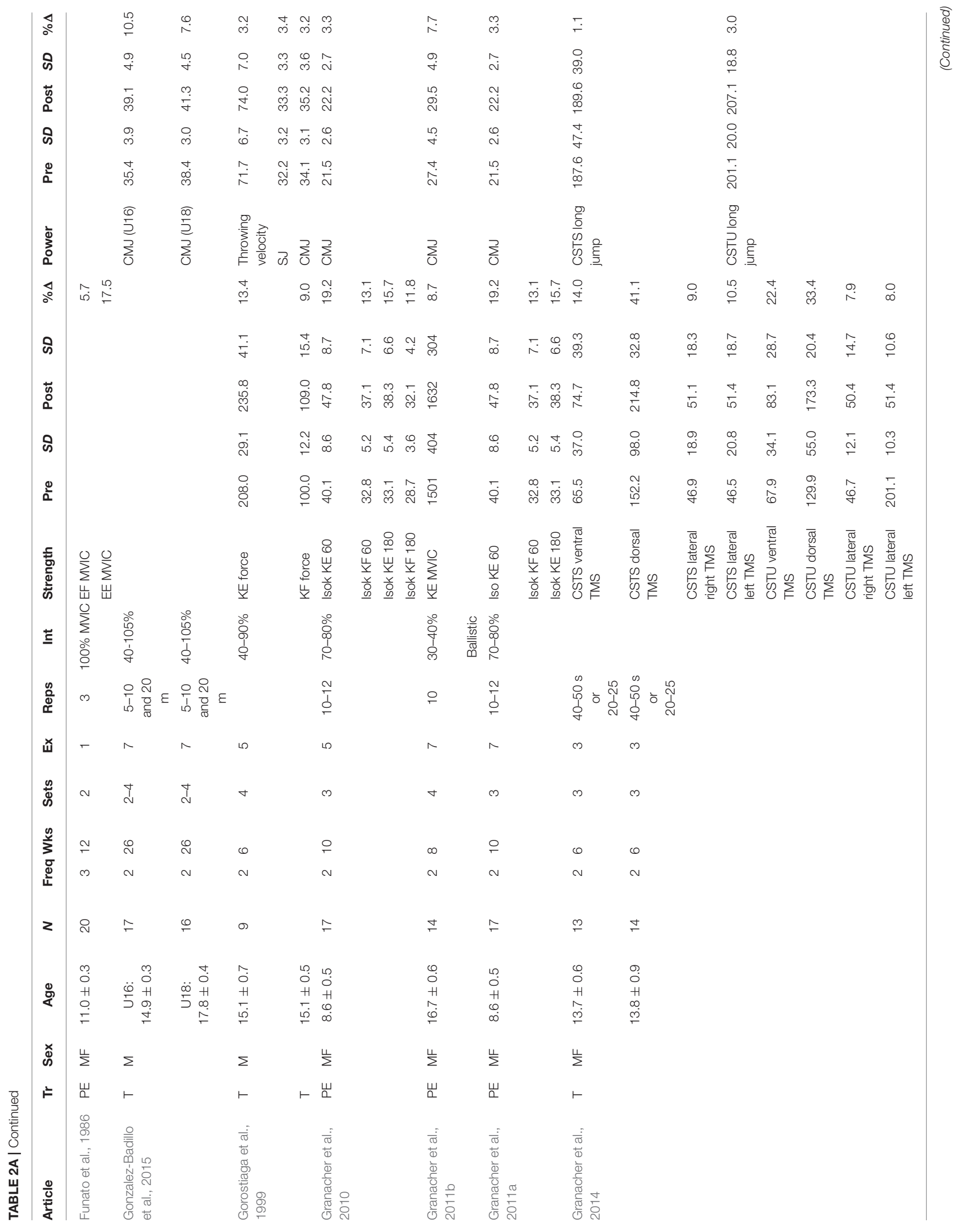

Frontiers in Physiology | www.frontiersin.org

8

June 2017 | Volume 8 | Article 423 


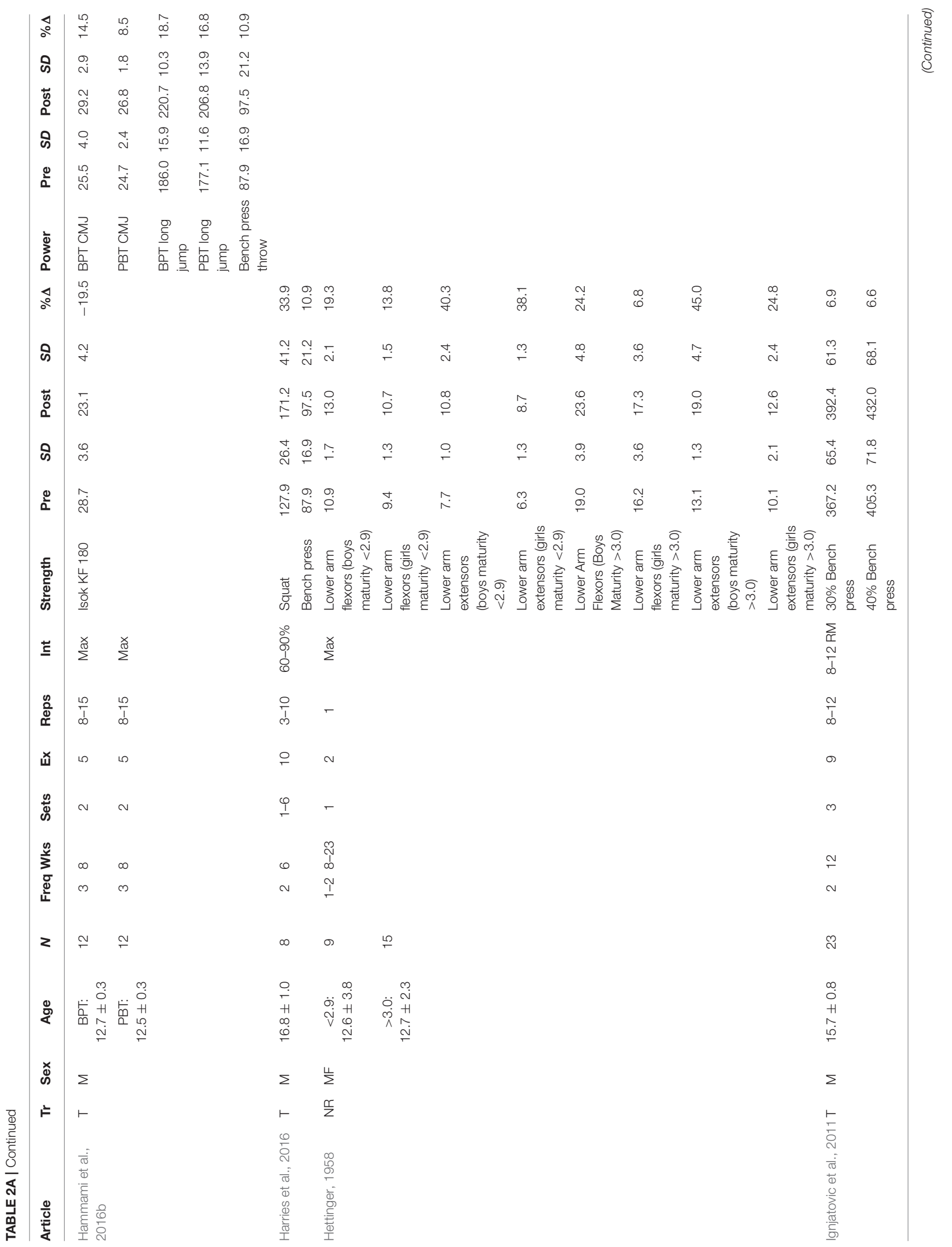




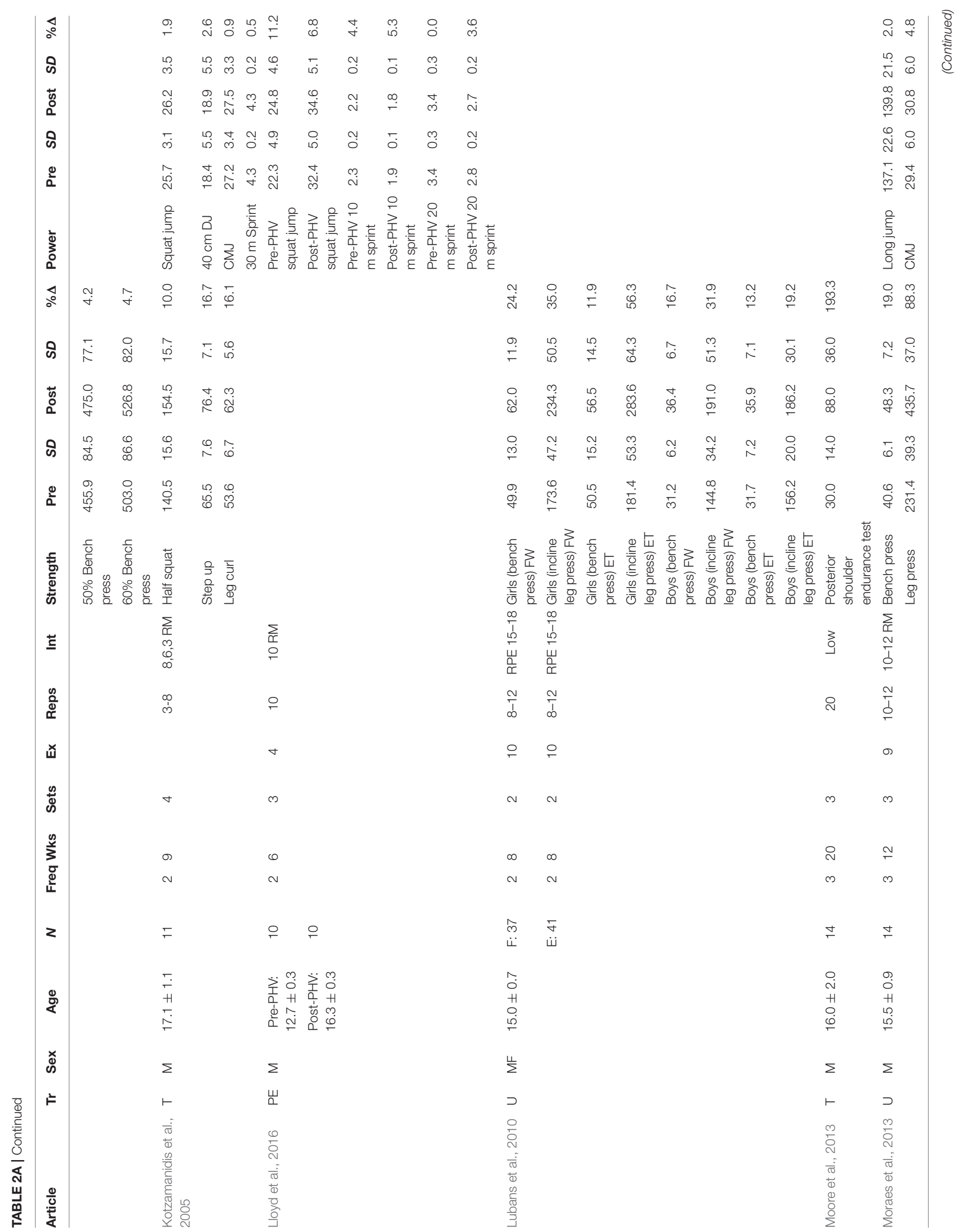




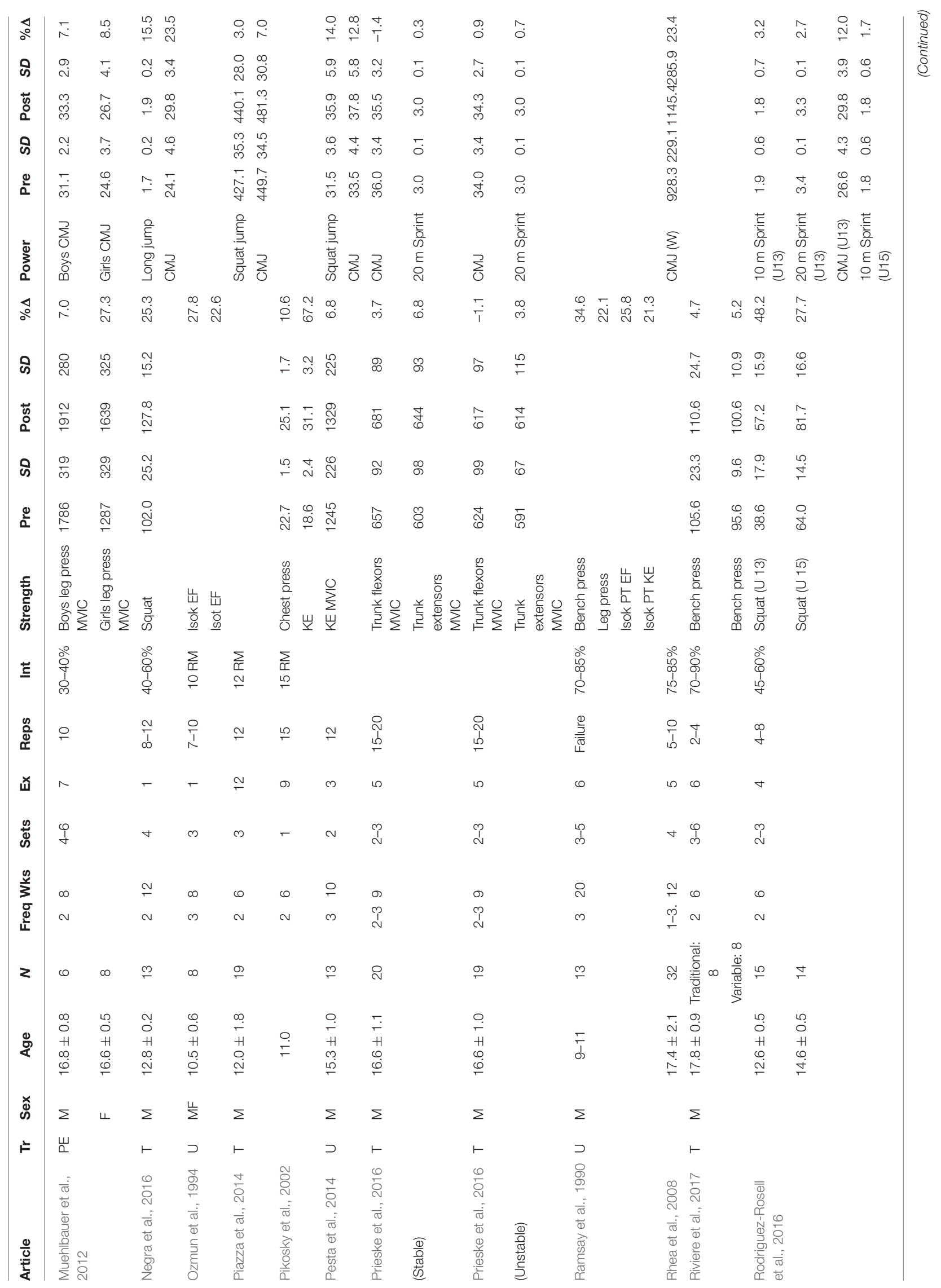




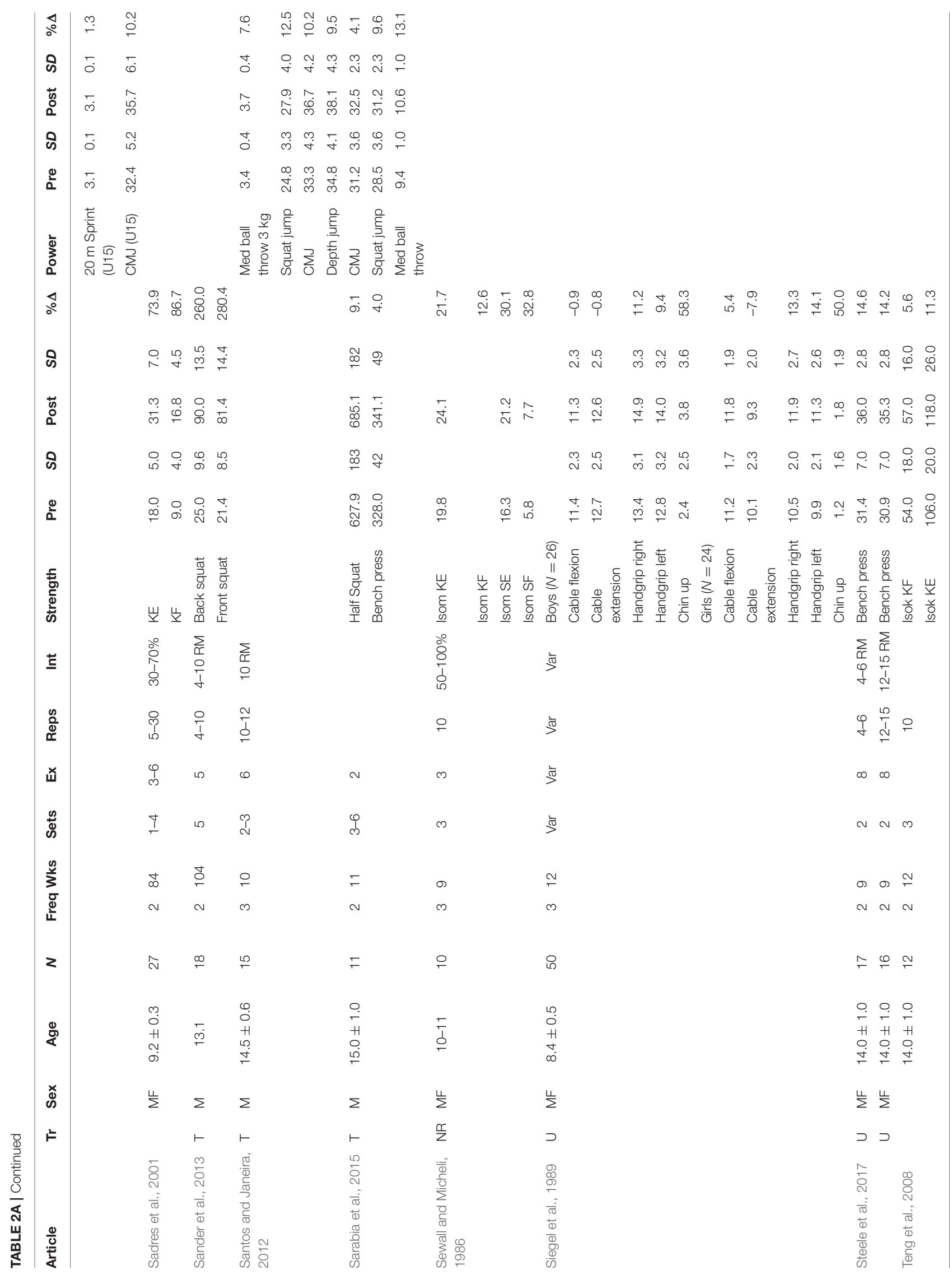




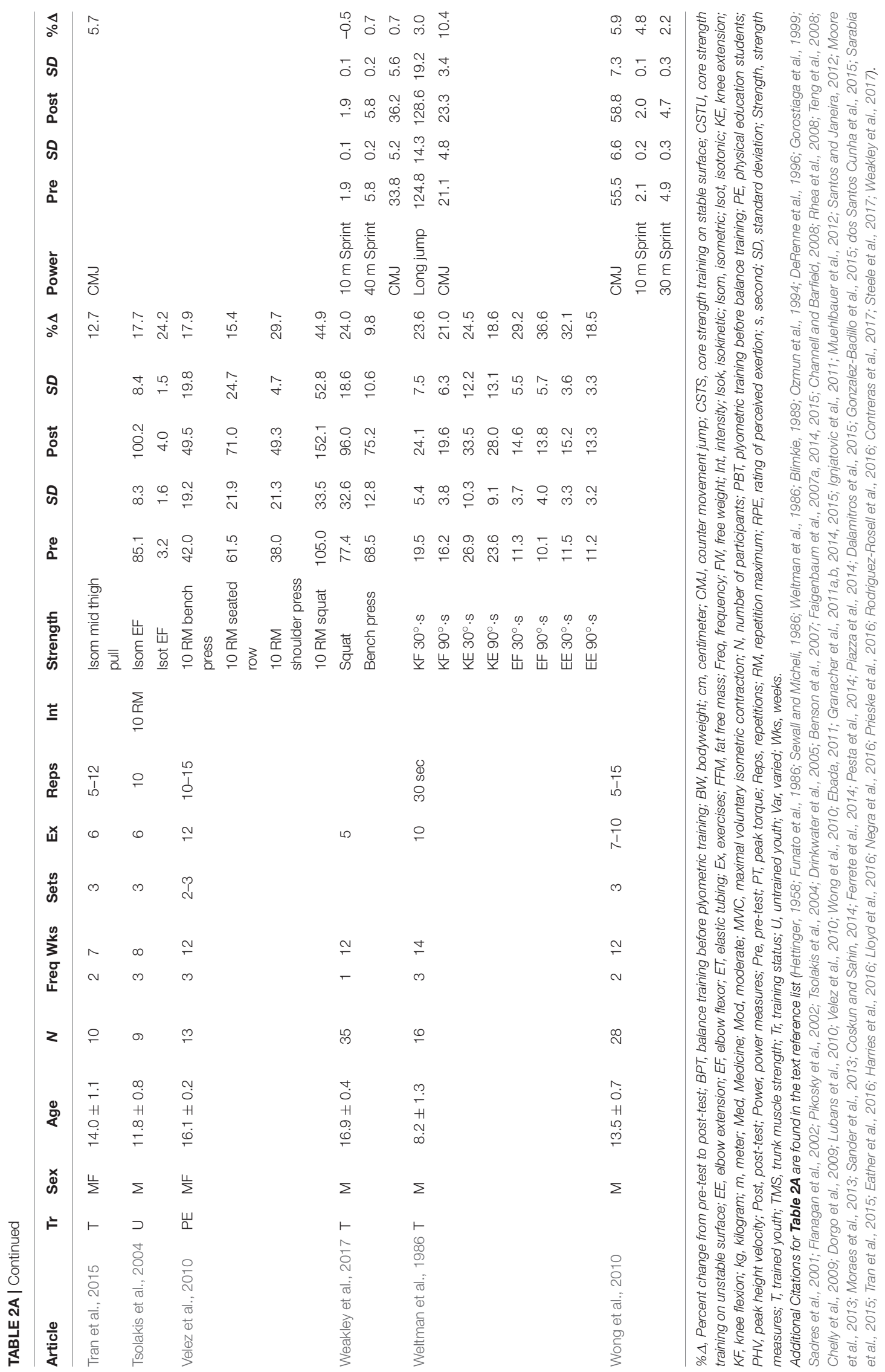




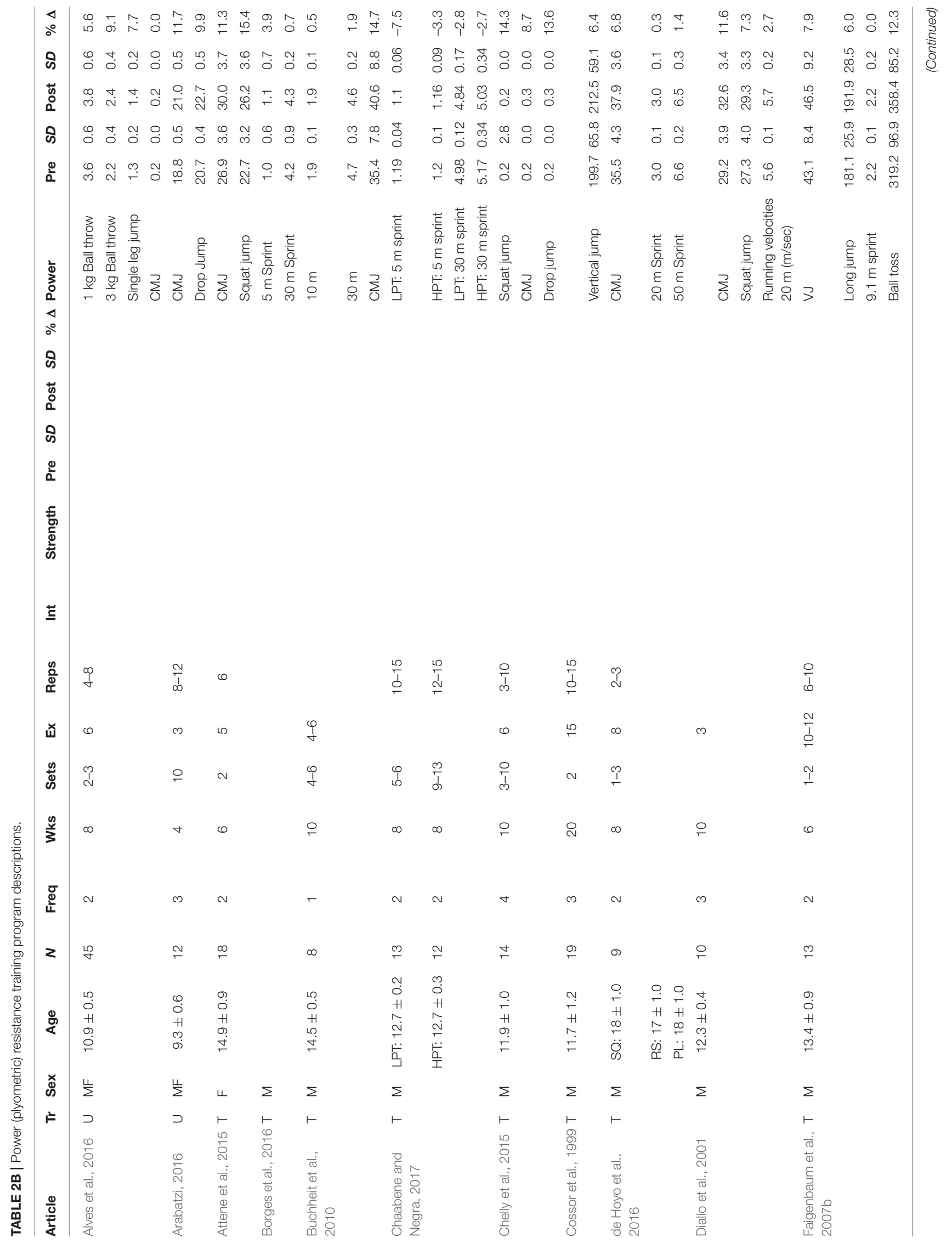




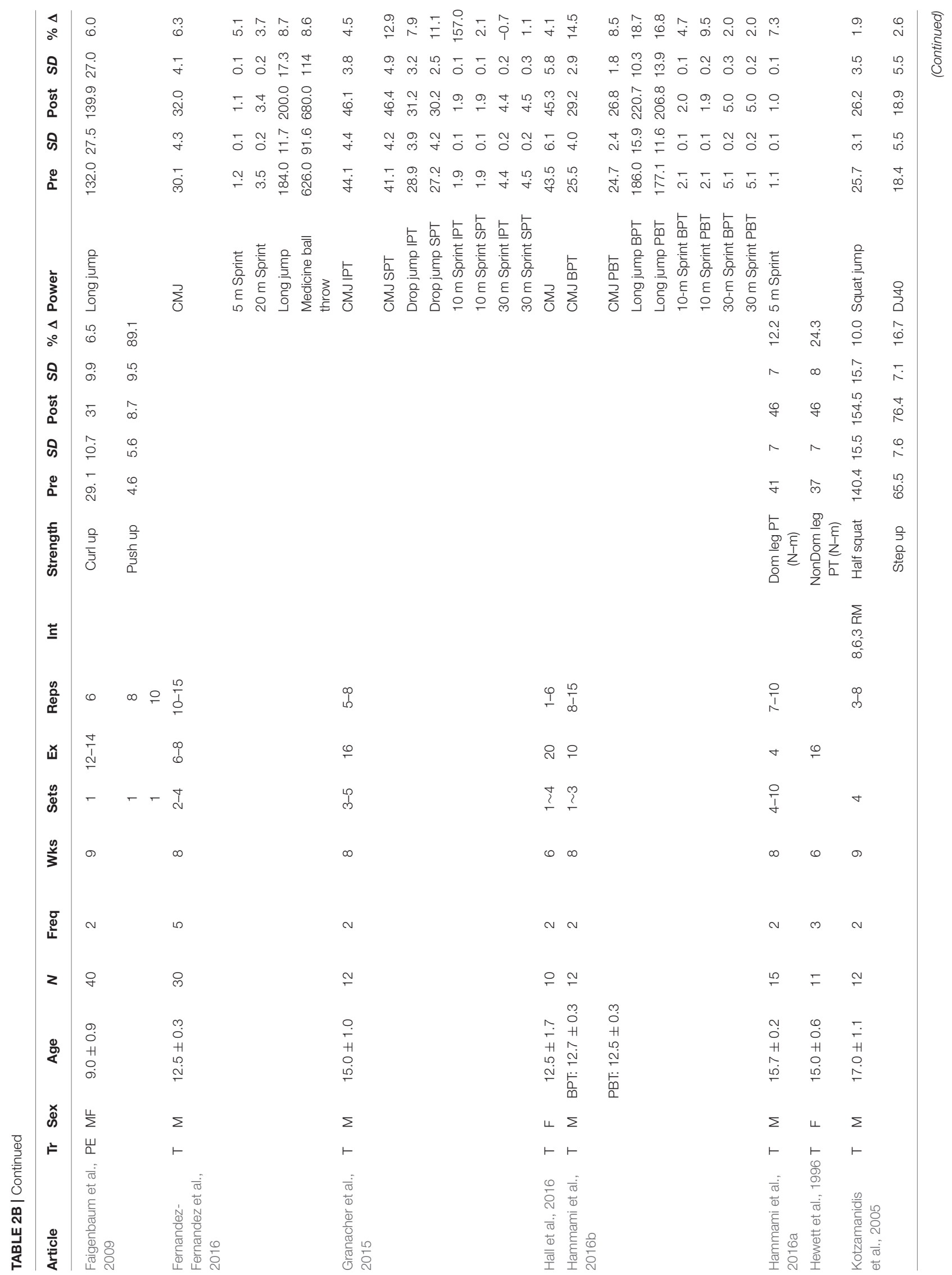




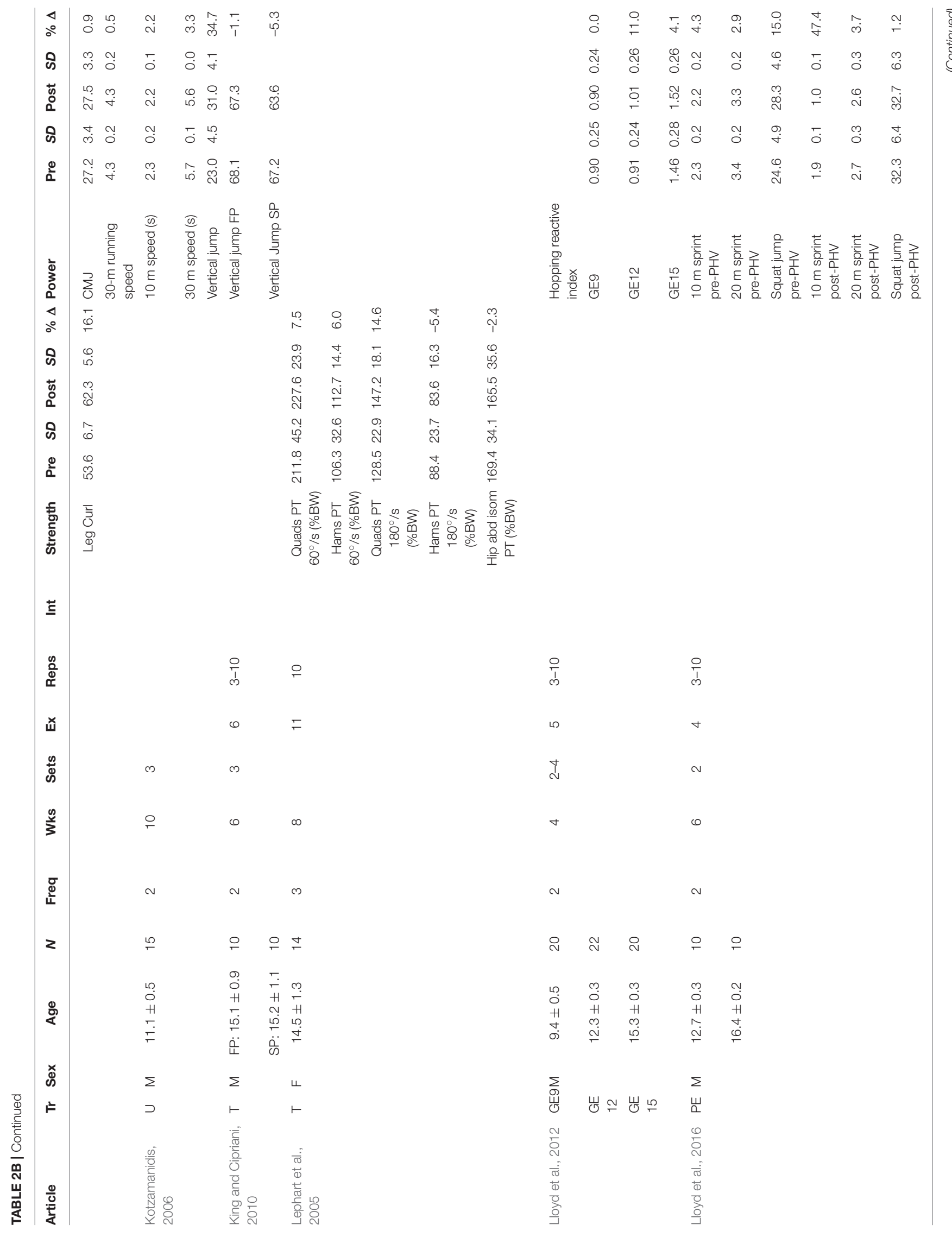




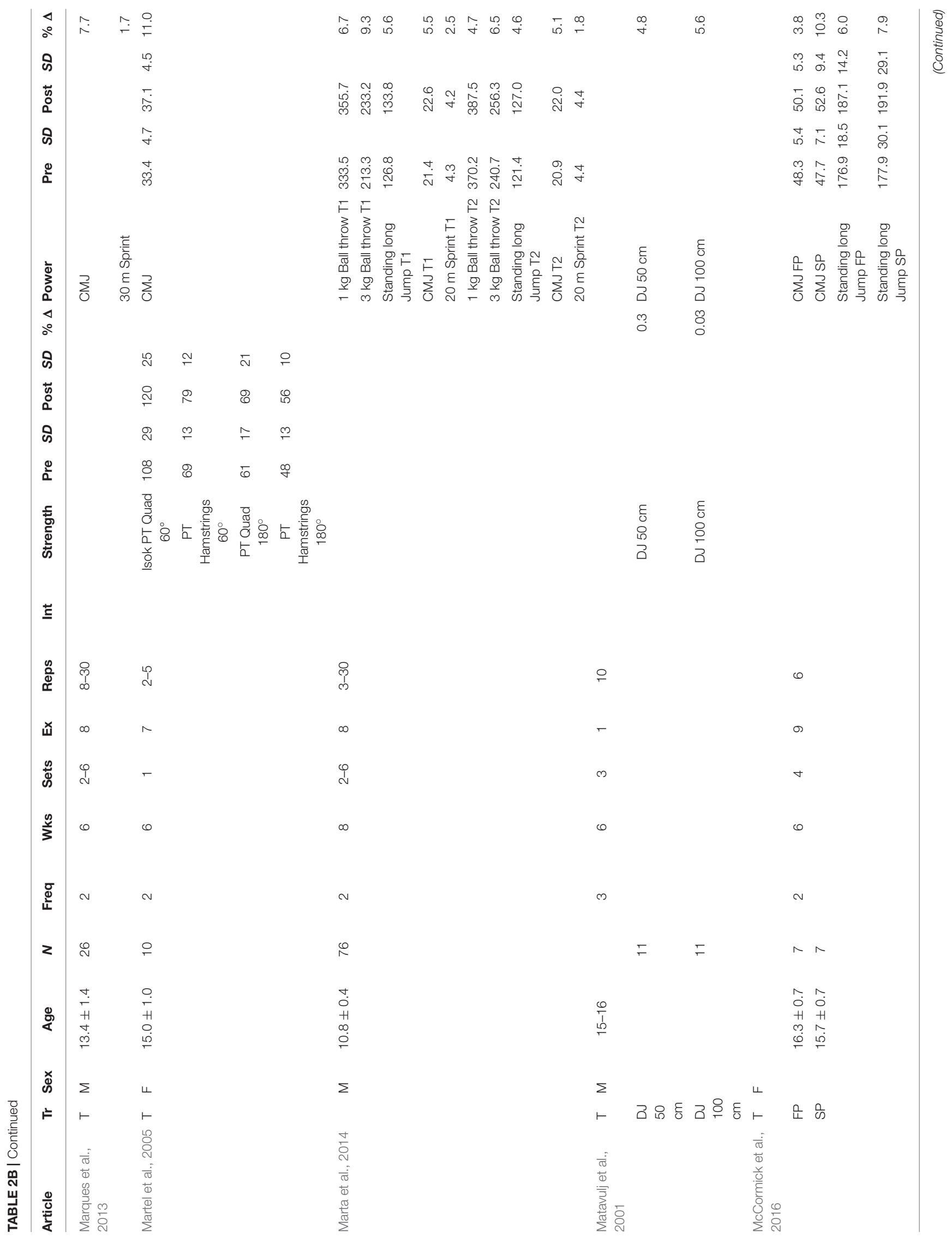




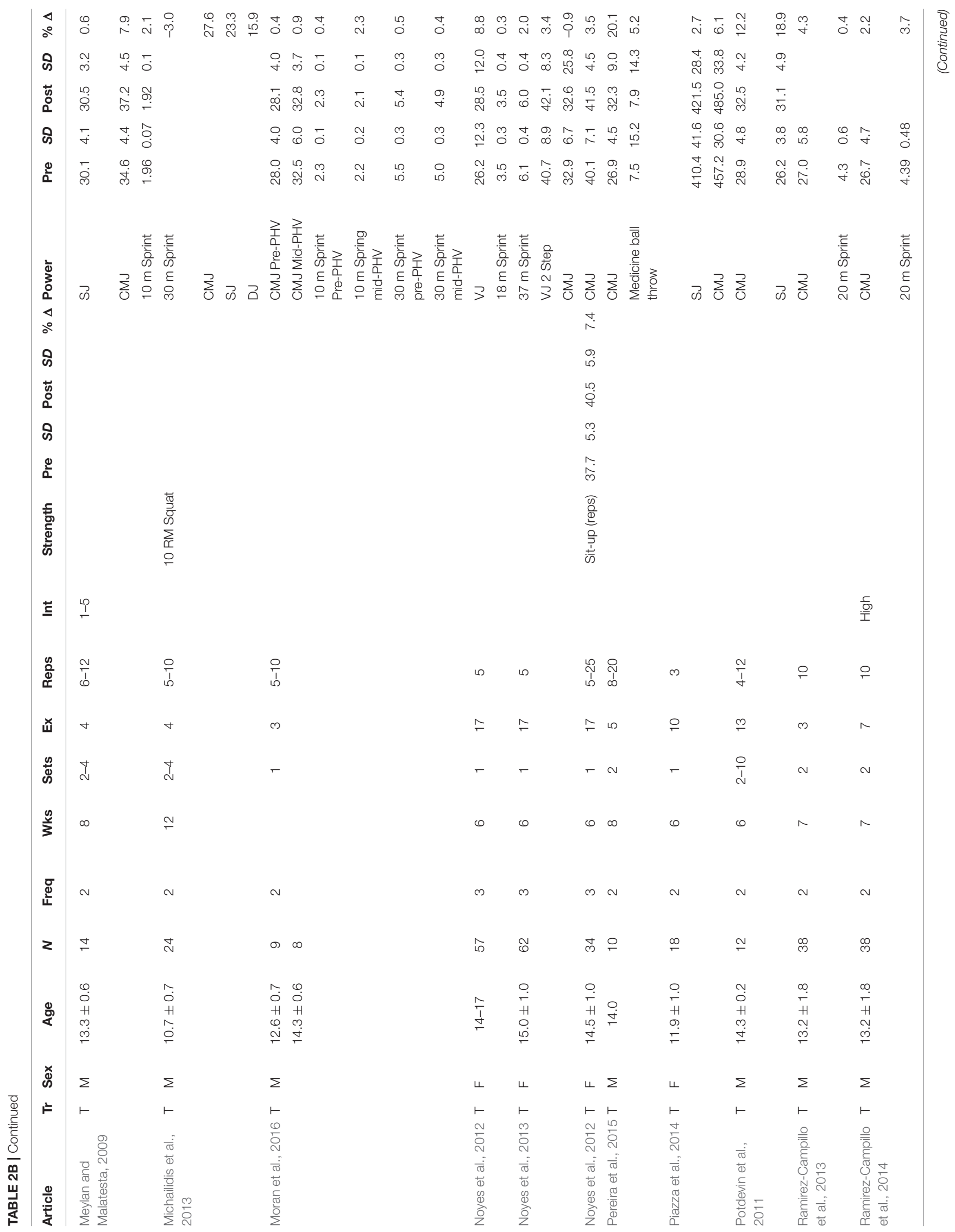




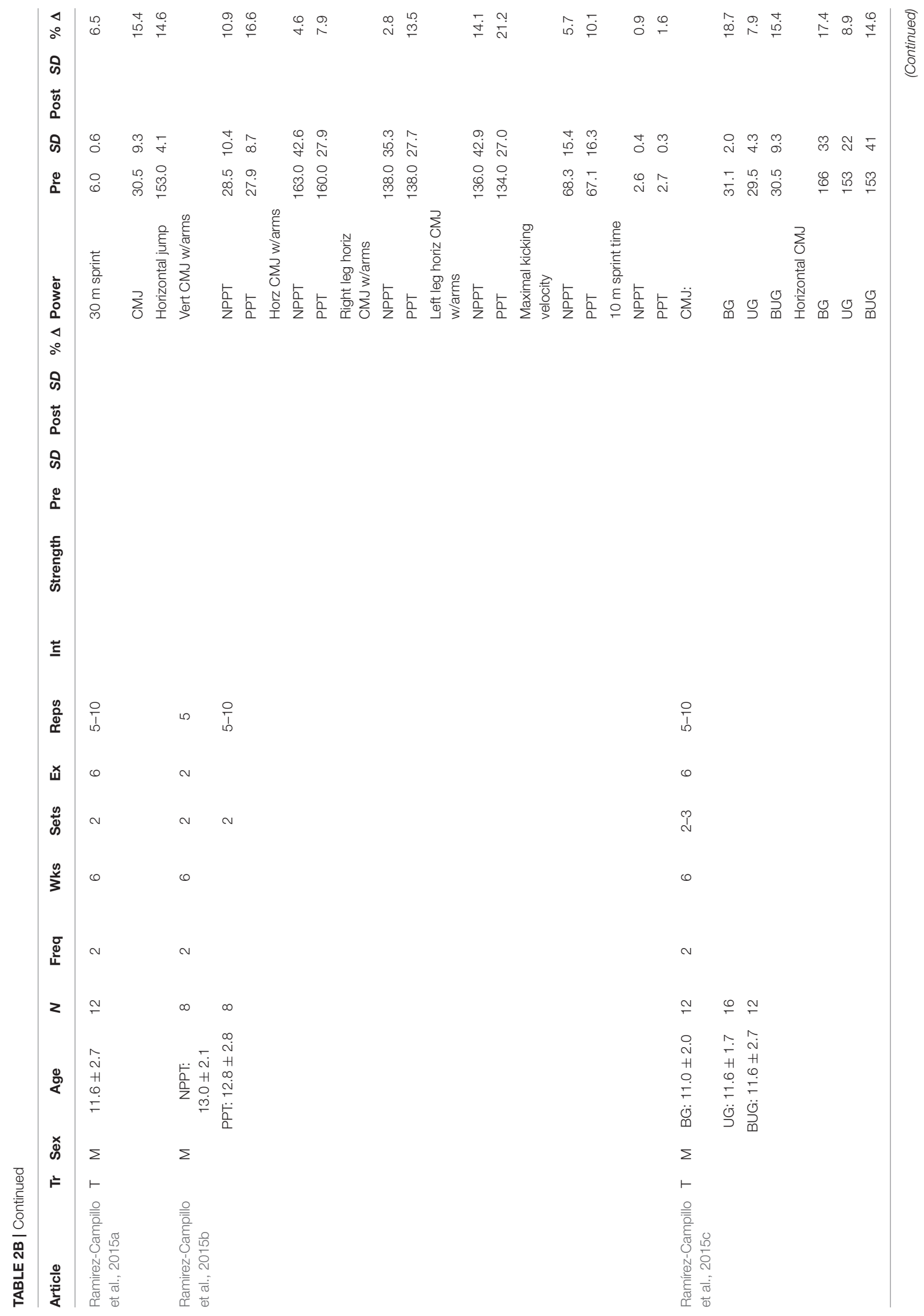




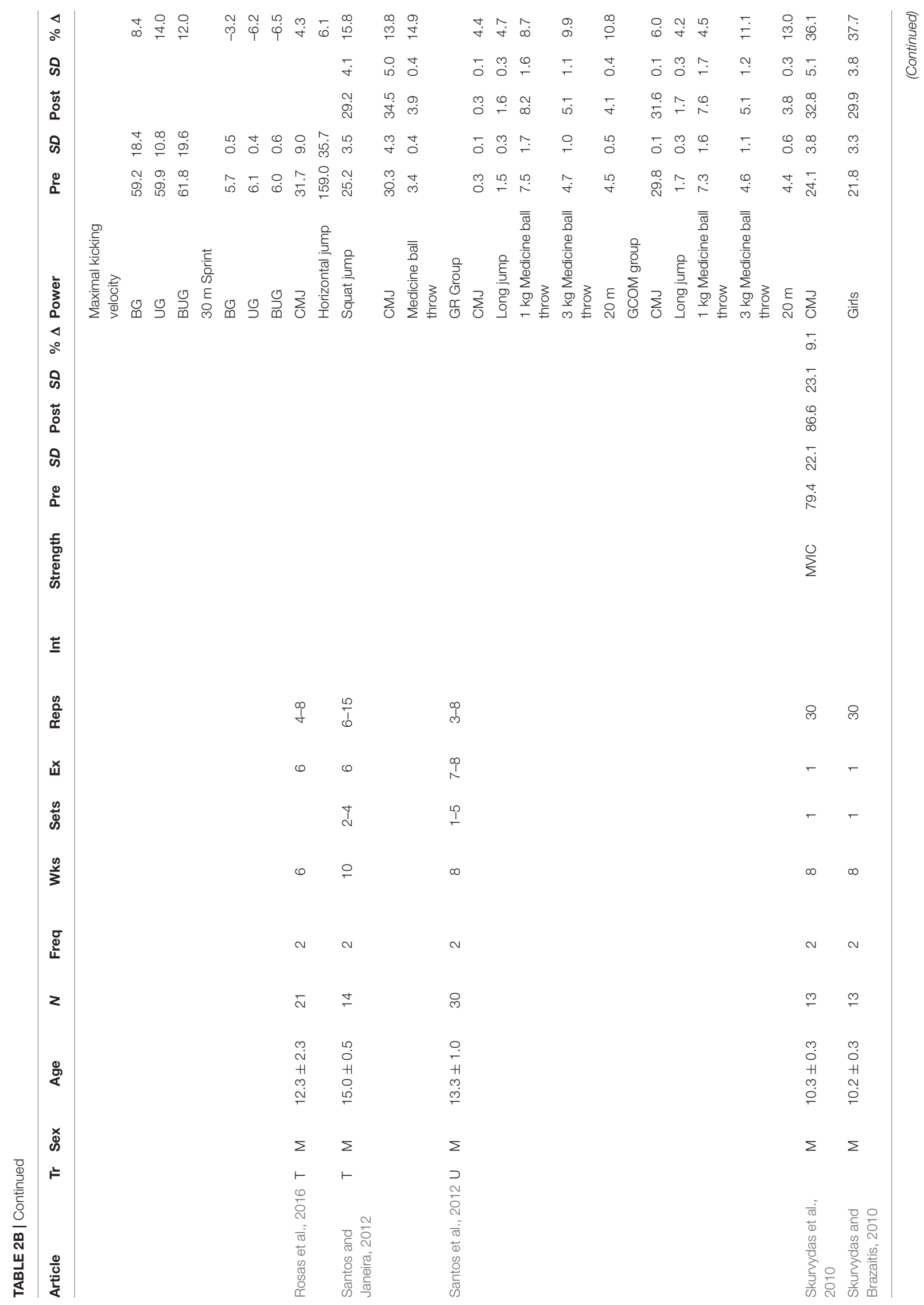




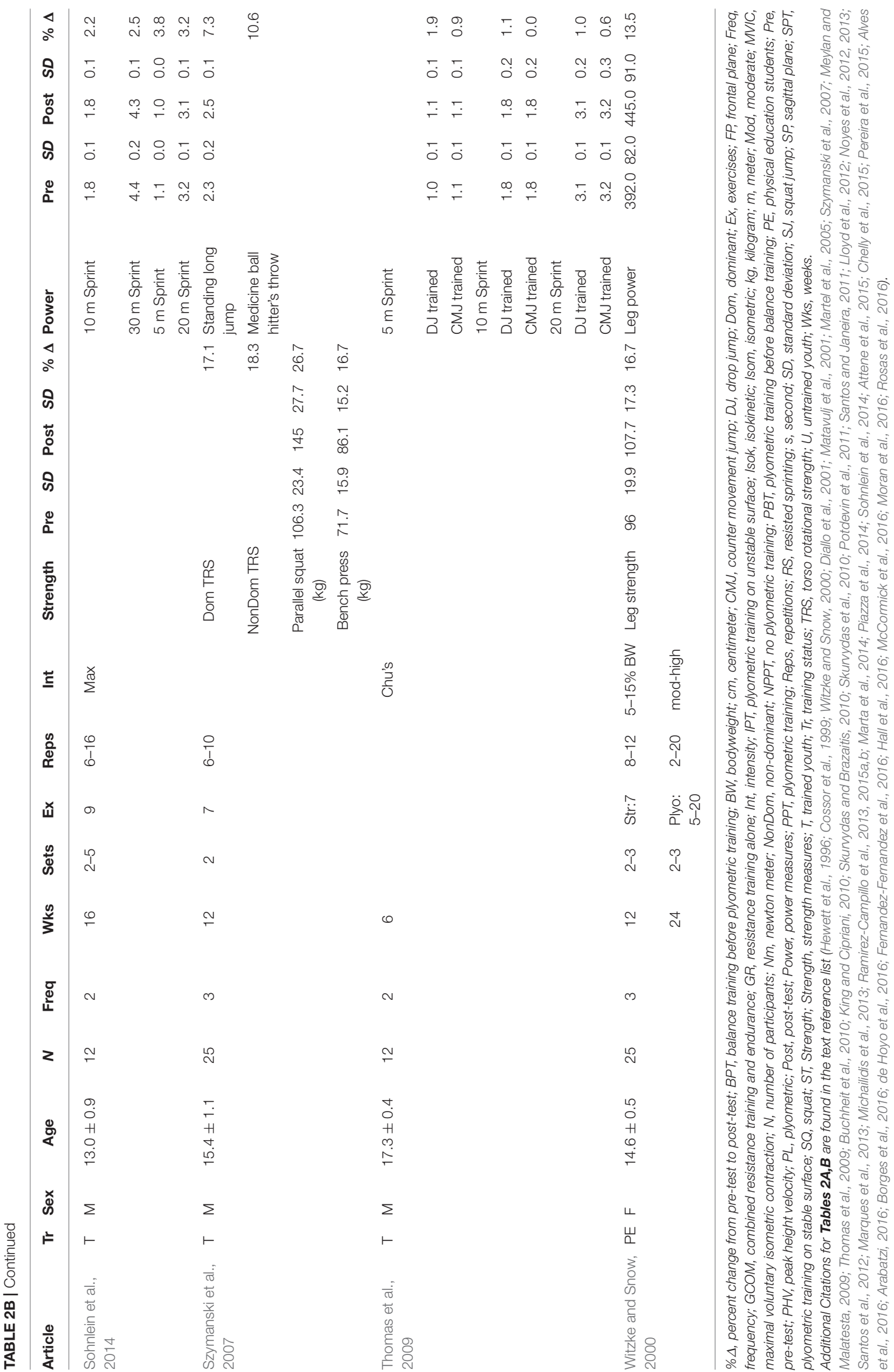


TABLE 3 | Summary of meta-analysis results.

\begin{tabular}{|c|c|c|c|c|c|}
\hline & General & Trained vs. & Untrained & Children vs. & Adolescents \\
\hline Power training effects on jump measures & 0.69 Moderate & 0.67 Moderate & 0.80 Large & $\underline{0.74}$ Moderate & 0.57 Moderate \\
\hline Strength training effects on jump measures & 0.53 Moderate & 0.48 Small & 0.61 Moderate & 0.68 Moderate & 0.42 Small \\
\hline Power training effects on sprint measures & 0.38 Small & 0.32 Small & $1.19^{*}$ Large & $\underline{0.47}$ Small & 0.13 Trivial \\
\hline Strength training effects on sprint measures & 0.48 Small & 0.45 Small & $0.57^{\star}$ Moderate & $\underline{0.73}$ Moderate & 0.36 Small \\
\hline Power training effects on lower body strength measures & $0.16^{\star \star}$ Trivial & Not reported & Not reported & Not reported & $0.16^{\star \star}$ Trivial \\
\hline
\end{tabular}

Shaded row values illustrate higher magnitude changes compared to the corresponding measure. Bolded values illustrate higher magnitude changes for untrained vs. trained participants. Bolded and underlined values indicate higher magnitude changes for children vs. adolescents.

${ }^{\star} 3$ studies met inclusion criteria; ${ }^{\star *} 4$ studies met the inclusion criteria.

velocities, contraction types and other training characteristics most closely match the subsequent activity, sport or tests. The higher speed and power movements associated with power training would be expected to provide more optimal training adaptations for explosive type jump measures. Power training (e.g., plyometrics) can improve youth's ability to increase movement speed and power production (Behm et al., 2008). Chaouachi et al. (2014) reported similar findings when they compared training programs that involved two types of power training (Olympic weight lifting and plyometric) and traditional RT. In accordance with the present review and the concept of training specificity, both plyometric and Olympic weight lifting in the Chaouachi study provided greater magnitude improvements in CMJ than traditional RT.

It should be noted though, that while the numerical SMD values for power training exceeded strength training for power measures, the descriptor categorization overall was the same: moderate for both power and strength training. Thus, while it is conceded that power training demonstrates a numerical advantage over strength training for power measures (e.g., jump performance), the relative extent or degree of superiority was not overwhelming. The relative magnitude of improvement with power training (moderate to large: 0.6-0.8) for power measures (e.g., jumps) did not match the training specific extent or consistency of improvements associated with strength training on lower body strength (uniformly large: $0.88-1.35$ ). Hence, the training specific response of strength training (strength training effects on strength measures) was consistently more substantial than the power training specific response (power training effects on jump power measures). Furthermore, power training specificity did not extend to another power and speed related measure: sprint speed.

Strength training magnitudes of change exceeded power training for sprint measures (exception of untrained participants). These findings contradict the long-held concept of training specificity (Sale and MacDougall, 1981; Behm, 1988, 1995; Behm and Sale, 1993). Slower, more deliberate movements of traditional RT would not be expected to provide optimal training adaptations for sprint measures that involve higher speed, stretch-shortening cycle (SSC) type activities. Again, similar findings were reported by Chaouachi et al. (2014) who found that traditional RT provided superior training adaptations compared to both Olympic weight lifting and plyometric training for 5 and 20 meter sprints. However, Radnor et al. (2017) reported contradictory results to the present metaanalysis with plyometric training and combined strength and plyometric training providing more positive responders than strength training alone for sprint velocity. The Radnor study incorporated school aged boys (not specifically trained) whereas the present review included both highly trained athletes and untrained youth. Similar to Radnor and colleagues, untrained youth in this meta-analysis participating in power training had greater magnitude improvements in sprint measures than trained athletes or the mean results of both populations.

One of the main factors contributing to optimal sprint performance is the capacity to generate a high rate of muscular force (Aagaard et al., 2002; Cronin and Sleivert, 2005; Cormie et al., 2007). Sprint actions employ stretch-shortening cycle (SSC) actions that involve the sequential combination of eccentric and concentric muscle contractions (Komi, 1986). SSC based actions tend to promote greater concentric force outputs when there is a rapid and efficient storage and transfer of elastic energy from the eccentric to the concentric phases (Cavagna et al., 1968; Bosco et al., 1982a,b; Cormie et al., 2010). Elastic and contractile (e.g., increased time for muscle activation, pre-load effect, muscle-tendon interaction, stretch reflexes) components affect maximal power output (Cavagna et al., 1968; Ettema et al., 1990; Lichtwark and Wilson, 2005; Avela et al., 2006). These mechanical and reflexive contributions occur over a short duration and thus the transition from eccentric to concentric phases must be brief (McCarthy et al., 2012). Reaction forces from sprints and hurdle jumps can generate reaction forces of 4-6 times the individual's body mass (Mero et al., 1992; Cappa and Behm, 2011). Since the predominant jump measures were from bilateral CMJ and squat jumps, the ground reaction forces upon each limb would have been substantially lower (typically $1 / 2$ ) than with high speed sprinting (with unilateral landings) (Dintiman and Ward, 2003; Cappa and Behm, 2011). The training specific related power (jump height) improvements seen with power training in this review would not necessitate similar eccentric strength capacities compared to the reaction forces experienced with sprinting. An individual who lacks sufficient eccentric strength must accommodate the eccentric forces by 


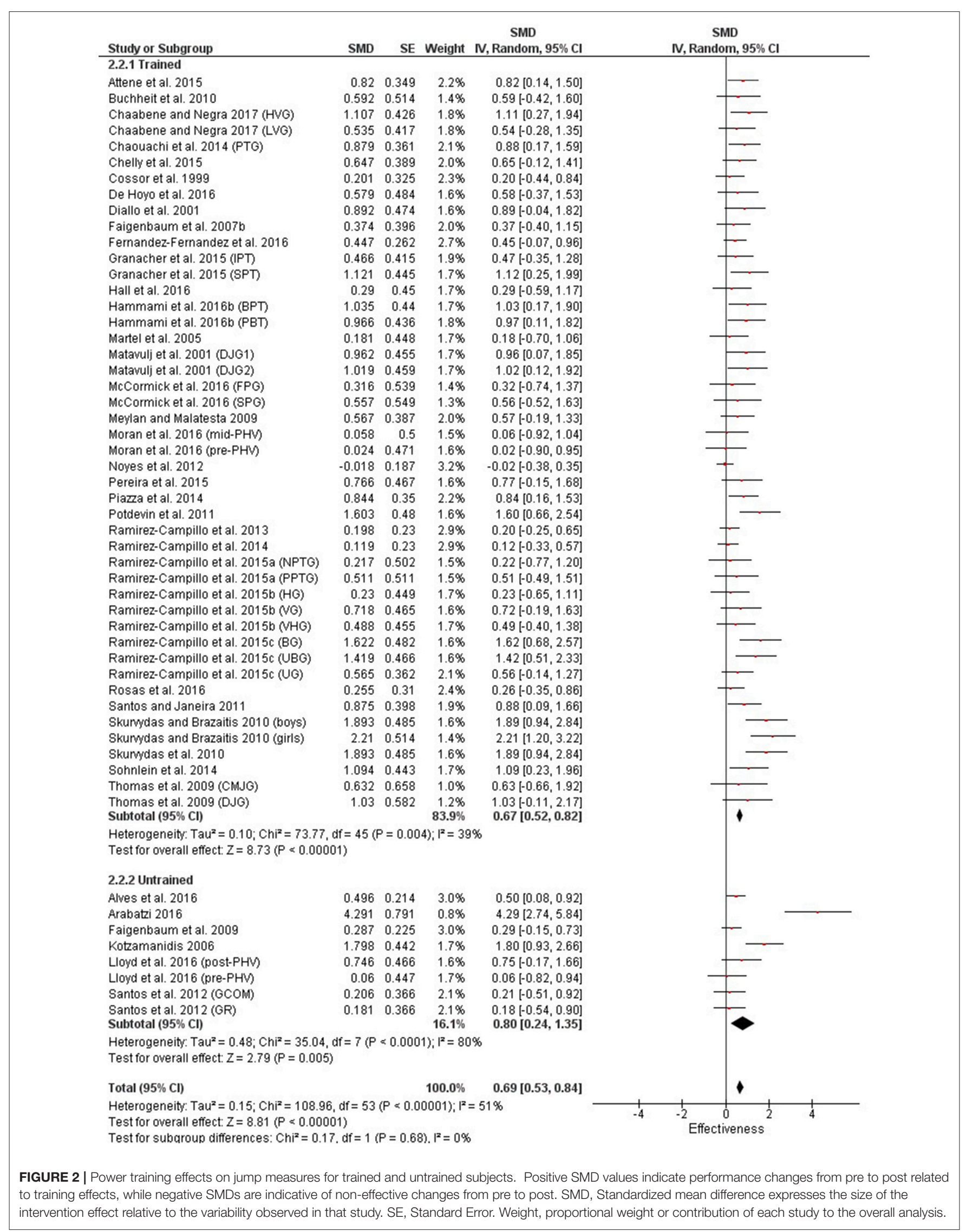




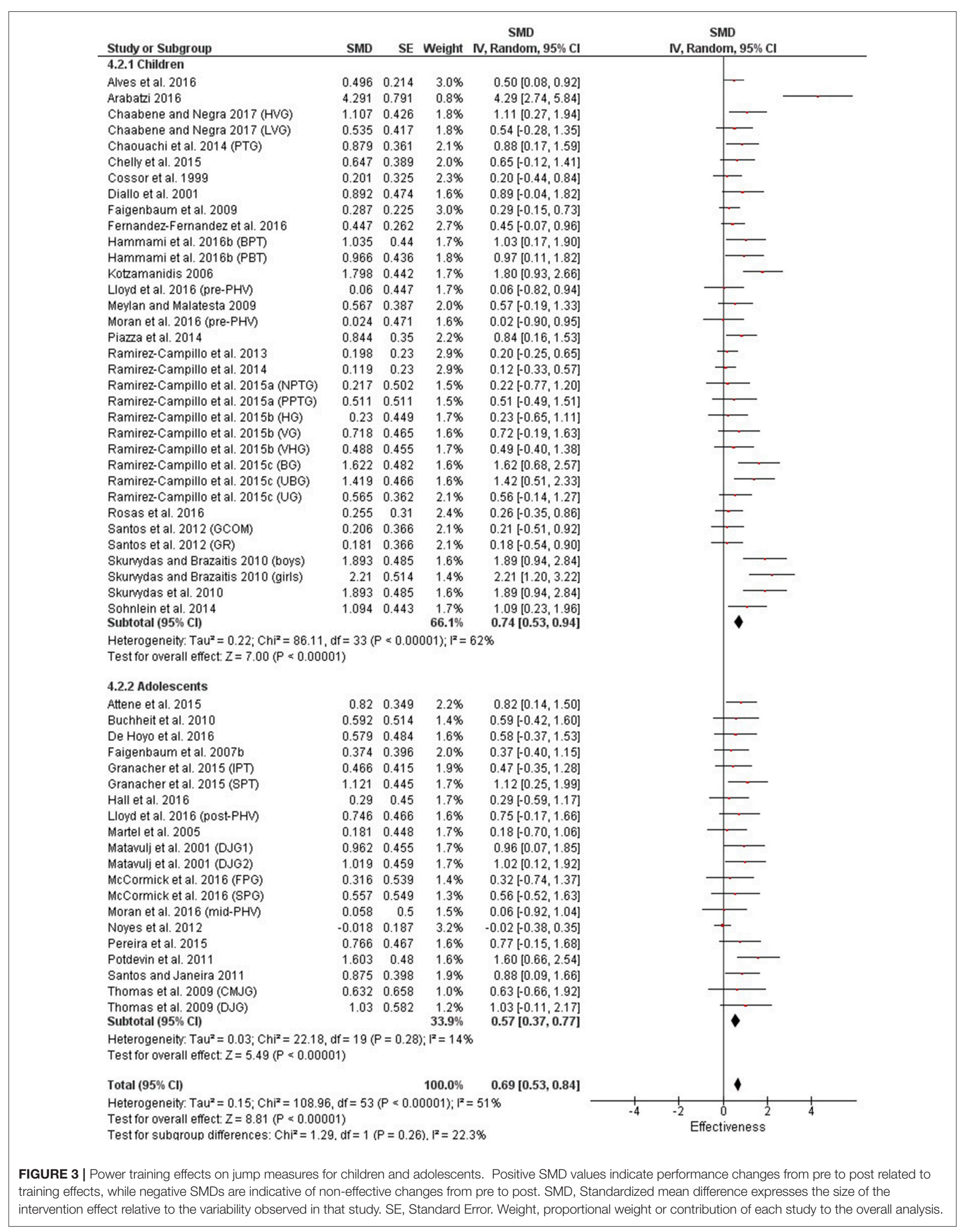




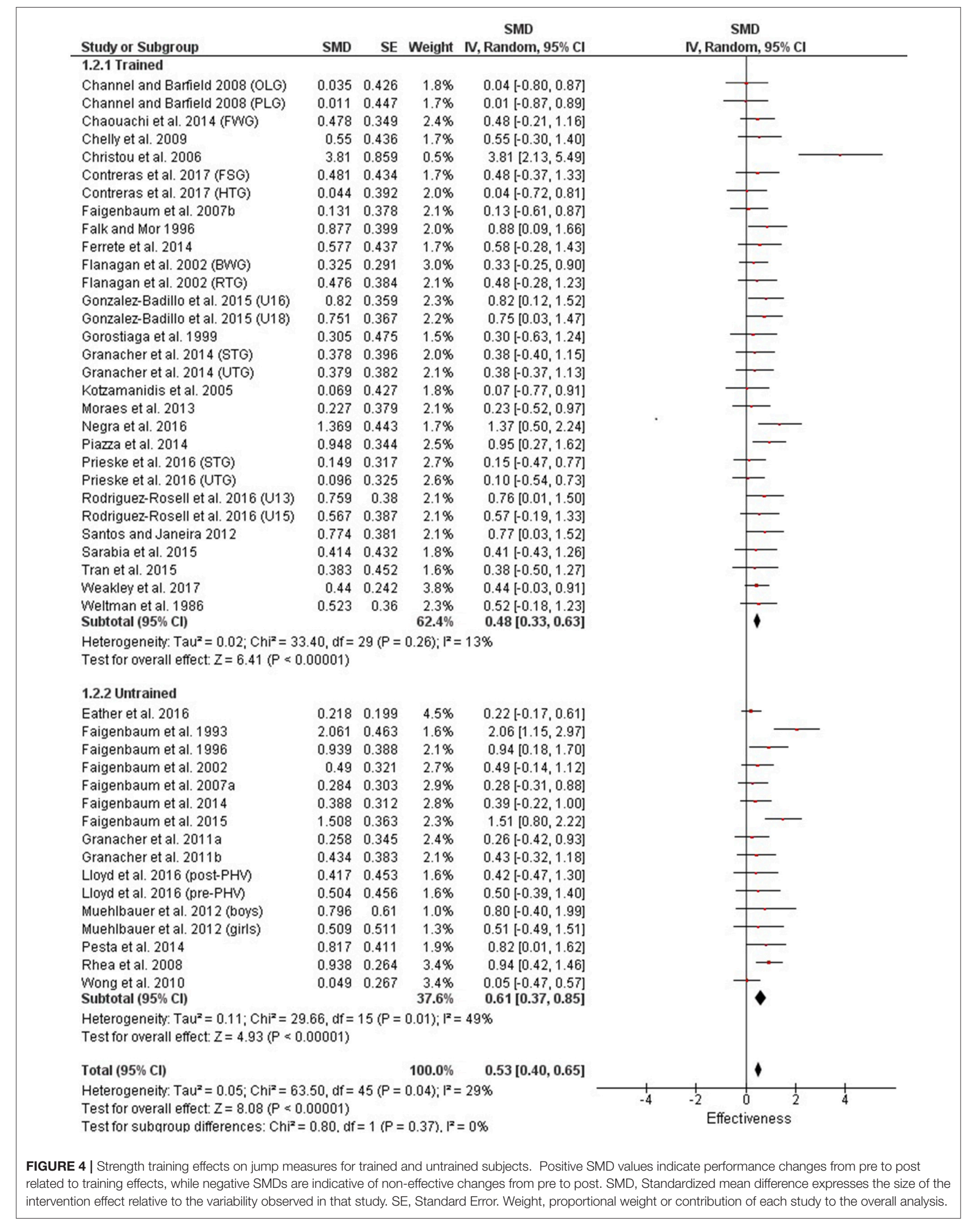




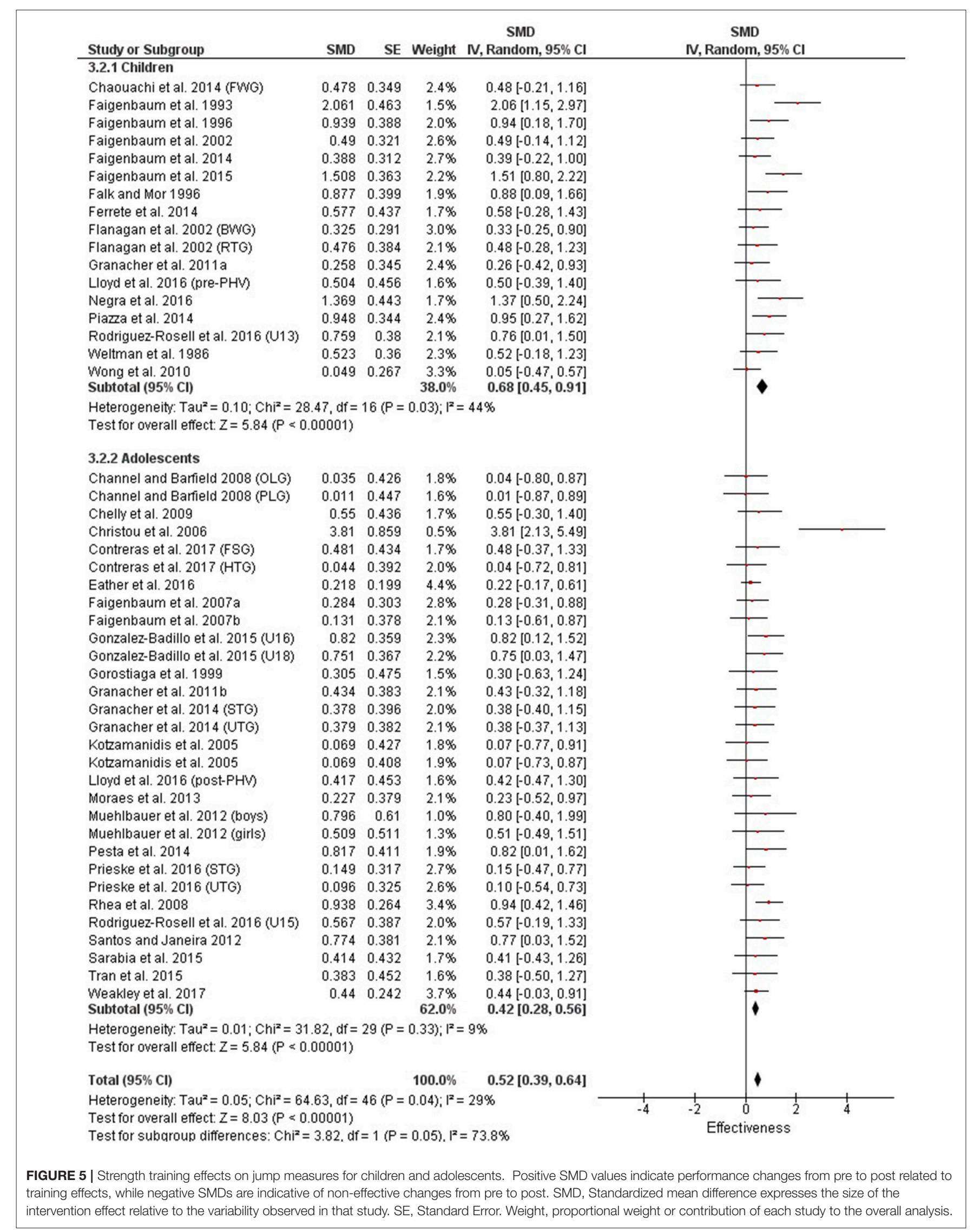




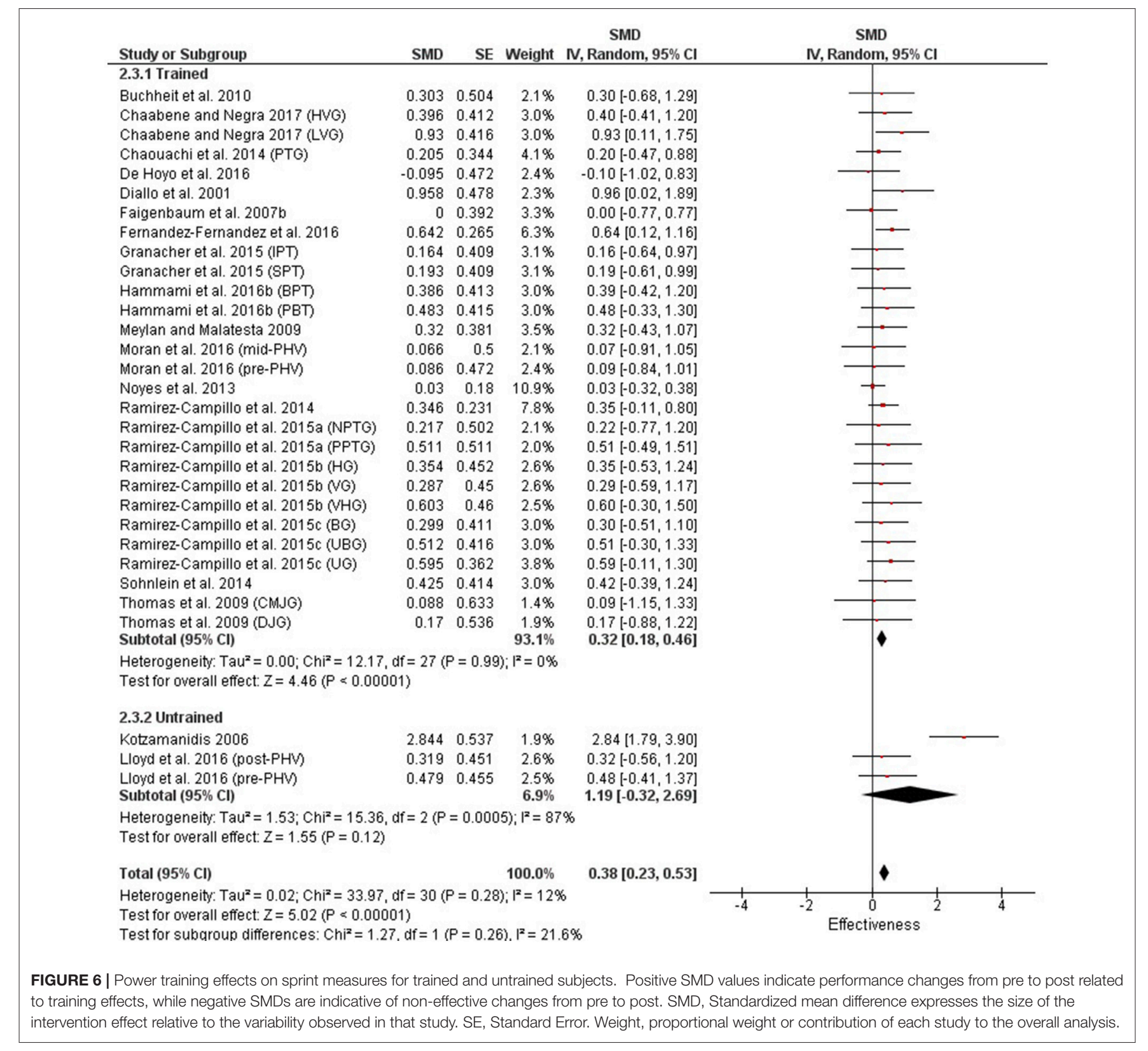

absorbing those forces over a longer time period, which would nullify the advantages of SSC actions (Miyaguchi and Demura, 2008). The lack of sprint training specificity with youth might be attributed to a lack of foundational eccentric (and likely concentric) strength. The effectiveness of traditional RT with youth sprinting would lie in its ability to build this essential strength component allowing youth to take advantage of the SSC mechanical and reflexive power amplification. Plyometric training would not be effective with any individual (youth or adult) who must absorb reaction forces over a prolonged period and thus cannot efficiently transfer the eccentric forces to the concentric power output.

The CMJ, drop, squat and other jumps evaluated in this meta-analysis all involved bilateral take-offs and landings. In contrast, sprinting is a series of rapid, unilateral landings and propulsions which would place greater challenges on the balance capabilities of the individual. Balance is another important contributor to SSC and sprint performance especially in youth (Hammami et al., 2016a). Balance affects force, power output and movement velocity (Anderson and Behm, 2005; Drinkwater et al., 2007; Behm et al., 2010a,b). Since balance and coordination are not fully mature in children (Payne and Isaacs, 2005), the effectiveness of plyometric training could be adversely affected. Hammami et al. (2016a) reported large-sized correlations between balance measures and proxies of power with youth ( $r=0.511-0.827)$. These correlation coefficients were greatest with the more mature post-peak height velocity (PHV) youth, suggesting that the poorer postural control of the less 
Study or Subgroup

4.3.1 Children

Chaabene and Negra 2017 (HVG)

Chaabene and Negra 2017 (LVG)

Chaouachi et al. 2014 (PTG)

Diallo et al. 2001

Fernandez-Fernandez et al. 2016

Hammami et al. 2016 b (BPT)

Hammami et al. 2016b (PBT)

Kotzamanidis 2006

Lloyd et al. 2016 (pre-PHV)

Meylan and Malatesta 2009

Moran et al. 2016 (pre-PHV)

Noyes et al. 2013

Ramirez-Campillo et al. 2014

Ramirez-Campillo et al. 2015a (NPTG)

Ramirez-Campillo et al. 2015a (PPTG)

Ramirez-Campillo et al. 2015b (HG)

Ramirez-Campillo et al. 2015b (VG)

Ramirez-Campillo et al. 2015b (VHG)

Ramirez-Campillo et al. 2015c (BG)

Ramirez-Campillo et al. 2015c (UBG)

Ramirez-Campillo et al. 2015c (UG)

Sohnlein et al. 2014

Subtotal $(95 \% \mathrm{Cl})$

Heterogeneity: $\mathrm{Tau}^{2}=0.06 ; \mathrm{Chi}^{2}=30.49, \mathrm{df}=21(\mathrm{P}=0.08) ;\left.\right|^{2}=31 \%$

Test for overall effect: $Z=4.83(P<0.00001)$

\begin{tabular}{|c|c|c|c|}
\hline \multicolumn{4}{|l|}{ 4.3.2 Adolescents } \\
\hline Buchheit et al. 2010 & 0.303 & 0.504 & $2.1 \%$ \\
\hline De Hoyo et al. 2016 & -0.095 & 0.472 & $2.4 \%$ \\
\hline Faigenbaum et al. $2007 \mathrm{~b}$ & 0 & 0.392 & $3.3 \%$ \\
\hline Granacher et al. 2015 (IPT) & 0.164 & 0.409 & $3.1 \%$ \\
\hline Granacher et al. 2015 (SPT) & 0.193 & 0.409 & $3.1 \%$ \\
\hline Lloyd et al. 2016 (post-PHV) & 0.319 & 0.451 & $2.6 \%$ \\
\hline Moran et al. 2016 (mid-PHV) & 0.066 & 0.5 & $2.1 \%$ \\
\hline Thomas et al. 2009 (CMJG) & 0.088 & 0.633 & $1.4 \%$ \\
\hline Thomas et al. 2009 (D.JG) & 0.17 & 0.536 & $1.9 \%$ \\
\hline Subtotal (95\% Cl) & & & $21.8 \%$ \\
\hline \multicolumn{4}{|c|}{$\begin{array}{l}\text { Heterogeneity: } \text { Tau }^{2}=0.00 ; \mathrm{Chi}^{2}=0.69, \mathrm{df}=8(\mathrm{P}=1.00) ; \mathrm{I}^{2}=0 \% \\
\text { Test for overall effect: } Z=0.86(P=0.39)\end{array}$} \\
\hline \multicolumn{3}{|l|}{ Total $(95 \% \mathrm{Cl})$} & $100.0 \%$ \\
\hline \multicolumn{4}{|c|}{$\begin{array}{l}\text { Heterogeneity: } \text { Tau }^{2}=0.02 ; C h i^{2}=33.97, d f=30(P=0.28) ; I^{2}=12 \% \\
\text { Test for overall effect: } Z=5.02(P<0.00001)\end{array}$} \\
\hline
\end{tabular}

SMD

SMD SE Weight IV, Random, $95 \% \mathrm{Cl}$

SMD

$0.396 \quad 0.412 \quad 3.0 \% \quad 0.40[-0.41,1.20]$

$0.93 \quad 0.416 \quad 3.0 \% \quad 0.93[0.11,1.75]$

$0.205 \quad 0.344 \quad 4.1 \% \quad 0.20[-0.47,0.88]$

$0.958 \quad 0.478 \quad 2.3 \% \quad 0.96[0.02,1.89]$

$0.642 \quad 0.265 \quad 6.3 \% \quad 0.64[0.12,1.16]$

$\begin{array}{llll}0.386 & 0.413 & 3.0 \% & 0.39[-0.42,1.20]\end{array}$

$0.483 \quad 0.415 \quad 3.0 \% \quad 0.48[-0.33,1.30]$

$2.844 \quad 0.537 \quad 1.9 \% \quad 2.84[1.79,3.90]$

$\begin{array}{llll}0.479 & 0.455 & 2.5 \% & 0.48[-0.41,1.37]\end{array}$

$\begin{array}{llll}0.32 & 0.381 & 3.5 \% & 0.32[-0.43,1.07]\end{array}$

$0.086 \quad 0.472 \quad 2.4 \% \quad 0.09[-0.84,1.01]$

$\begin{array}{llll}0.03 & 0.18 & 10.9 \% & 0.03[-0.32,0.38]\end{array}$

$\begin{array}{llll}0.346 & 0.231 & 7.8 \% & 0.35[-0.11,0.80]\end{array}$

$\begin{array}{llll}0.217 & 0.502 & 2.1 \% & 0.22[-0.77,1.20]\end{array}$

$0.511 \quad 0.511 \quad 2.0 \% \quad 0.51[-0.49,1.51]$

$0.354 \quad 0.452 \quad 2.6 \% \quad 0.35[-0.53,1.24]$

$0.287 \quad 0.45 \quad 2.6 \% \quad 0.29[-0.59,1.17]$

$0.603 \quad 0.46 \quad 2.5 \% \quad 0.60[-0.30,1.50]$

$0.299 \quad 0.411 \quad 3.0 \% \quad 0.30[-0.51,1.10]$

$0.512 \quad 0.416 \quad 3.0 \% \quad 0.51[-0.30,1.33]$

$0.595 \quad 0.362 \quad 3.8 \% \quad 0.59[-0.11,1.30]$

$0.42[-0.39,1.24]$

$0.47[0.28,0.67]$
$0.30[-0.68,1.29]$

$-0.10[-1.02,0.83]$

$0.00[-0.77,0.77]$

$0.16[-0.64,0.97]$

$0.19[-0.61,0.99]$

$0.32[-0.56,1.20]$

$0.07[-0.91,1.05]$

$0.09[-1.15,1.33]$

$0.17[-0.88,1.22]$

$0.13[-0.17,0.44]$

$0.38[0.23,0.53]$ , Random, $95 \% \mathrm{Cl}$

FIGURE 7 | Power training effects on sprint measures for children and adolescents. Positive SMD values indicate performance changes from pre to post related to training effects, while negative SMDs are indicative of non-effective changes from pre to post. SMD, Standardized mean difference expresses the size of the intervention effect relative to the variability observed in that study. SE, Standard Error. Weight, proportional weight or contribution of each study to the overall analysis.

mature pre-PHV and PHV youth had negative consequences upon power output. Similarly, significant positive correlations between maximum speed skating performance and a static wobble board balance test were reported in youth under 19 years of age (Behm et al., 2005). Thus, plyometric training activities are positively augmented with greater balance or postural control. For example, when 4 weeks of balance training was incorporated prior to 4 weeks of plyometric training the training outcomes were significantly better with youth than in the reverse order (Hammami et al., 2016b). Hence, the combination of inadequate strength and balance would inhibit positive sprint training adaptations associated with plyometric training with youth. In conflict with the training specificity principle, traditional RT may be more beneficial for promoting sprint adaptations in youth since it can build a foundation of strength upon which youth can take greater advantage of the SSC. Furthermore, the use of free weight or ground based strength/RT would be highly recommended for youth in order to emphasize initial balance adaptations (Behm et al., 2008, 2010a,b).

The only exception to the strength training advantage for sprint performance was with untrained participants with strength training providing moderate benefits (0.57) compared to large benefits (1.19) with plyometric training. However, upon closer inspection, there were only 3 measures each available for the untrained strength and plyometric training participants vs. 11 and 30 measures for the trained strength and plyometric trained participants, respectively. Hence, with such a sparsity of 


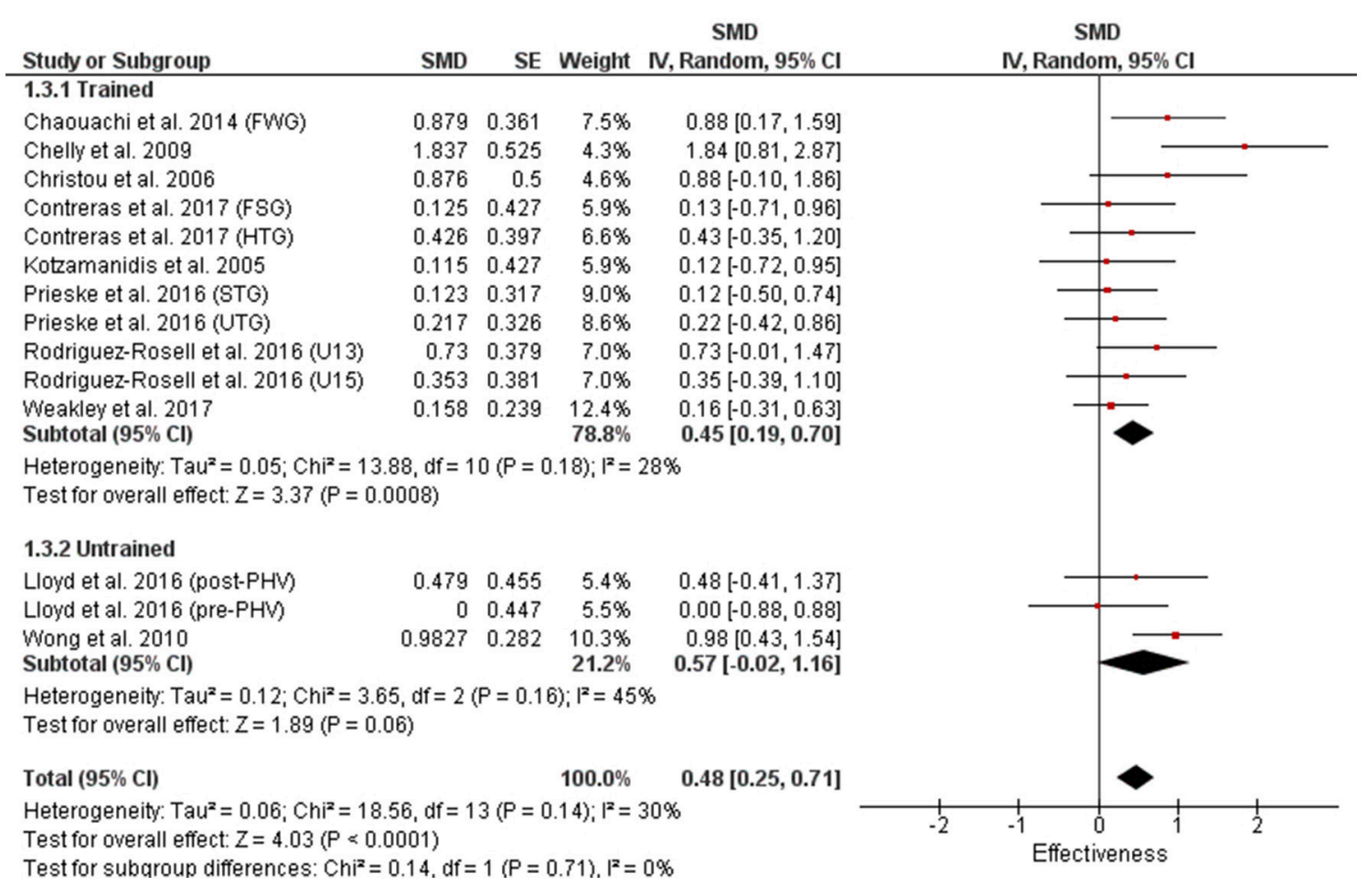

FIGURE 8 | Strength training effects on sprint measures for trained and untrained subjects. Positive SMD values indicate performance changes from pre to post related to training effects, while negative SMDs are indicative of non-effective changes from pre to post. SMD, Standardized mean difference expresses the size of the intervention effect relative to the variability observed in that study. SE, Standard Error. Weight, proportional weight or contribution of each study to the overall analysis.

measures, one must be cautious about interpreting the robustness of this specific result for the untrained youth population.

There are a few youth training studies that combine plyometric and RT. As expected, the combination of plyometrics and RT provided significantly greater improvements in sprint speed and vertical jump height performance than untrained controls with 6 and 12 weeks of training, respectively (Wong et al., 2010; Hopper et al., 2017). Radnor et al. (2017) compared 6 weeks of plyometric, RT and combined training and found more positive responders for $30 \mathrm{~m}$ sprint speed with the combined pre-PHV group. In the post-PHV group, the combined training provided more positive responders with acceleration $(10 \mathrm{~m}$ sprint) and squat jumps vs. the plyometric only and RT groups. Similarly, Kotzamanidis et al. (2005) reported that the combination of 13 weeks of RT and speed training provided greater training benefits for $30 \mathrm{~m}$ sprint, squat jump and CMJ than RT alone. The combination of plyometric and RT in these studies did not provide substantially greater training adaptations than the plyometric only training meta-analysis results expressed in this meta-analysis. While Wong et al. (2010) reported small to moderate magnitude improvements for vertical jump height, 10 and $30 \mathrm{~m}$ sprint performance, Kotzamanidis et al. (2005) reported $3-7 \%$ improvements in sprint and jump performances vs. $1-2 \%$ improvements for the RT only group. Thus, the combination of plyometric and strength training exercises did not seem provide additive benefits compared to either plyometric or RT alone.
Untrained youth in this meta-analysis produced greater training gains with jump and sprint measures (for both strength and power training) than trained youth. Table 2 illustrates that not only were the numerical effect sizes greater but in each case the threshold for the magnitude descriptor was exceeded and moved into a higher category with the untrained (i.e., moderate vs. large, small vs. moderate, small vs. large). Since the untrained individuals are beginning a training program and are situated at a lower baseline of functional performance, the initial degree of improvement would be expected to be greater than with trained individuals whose physical capacities have already progressed beyond their initial baseline. Similarly, Behringer et al. (2011) reported a similar trend and offered there might a ceiling effect of functional adaptations in experienced subjects, whereas novices and non-athletes experience greater adaptations due to greater learning effects. The only exception to the untrained groups training accrual benefits was for the effect of strength training upon lower body strength measures, where both groups had large magnitude changes. The training adaptation emphasis may differ between these two groups with untrained youth optimizing motor control/learning and coordination, whereas trained youth may emphasize more the neural (recruitment, rate coding synchronization) and morphological adaptations. So, although the trained youth may be closer to their training potential ceiling, they may be able to tap into adaptations not yet fully available to the untrained. 


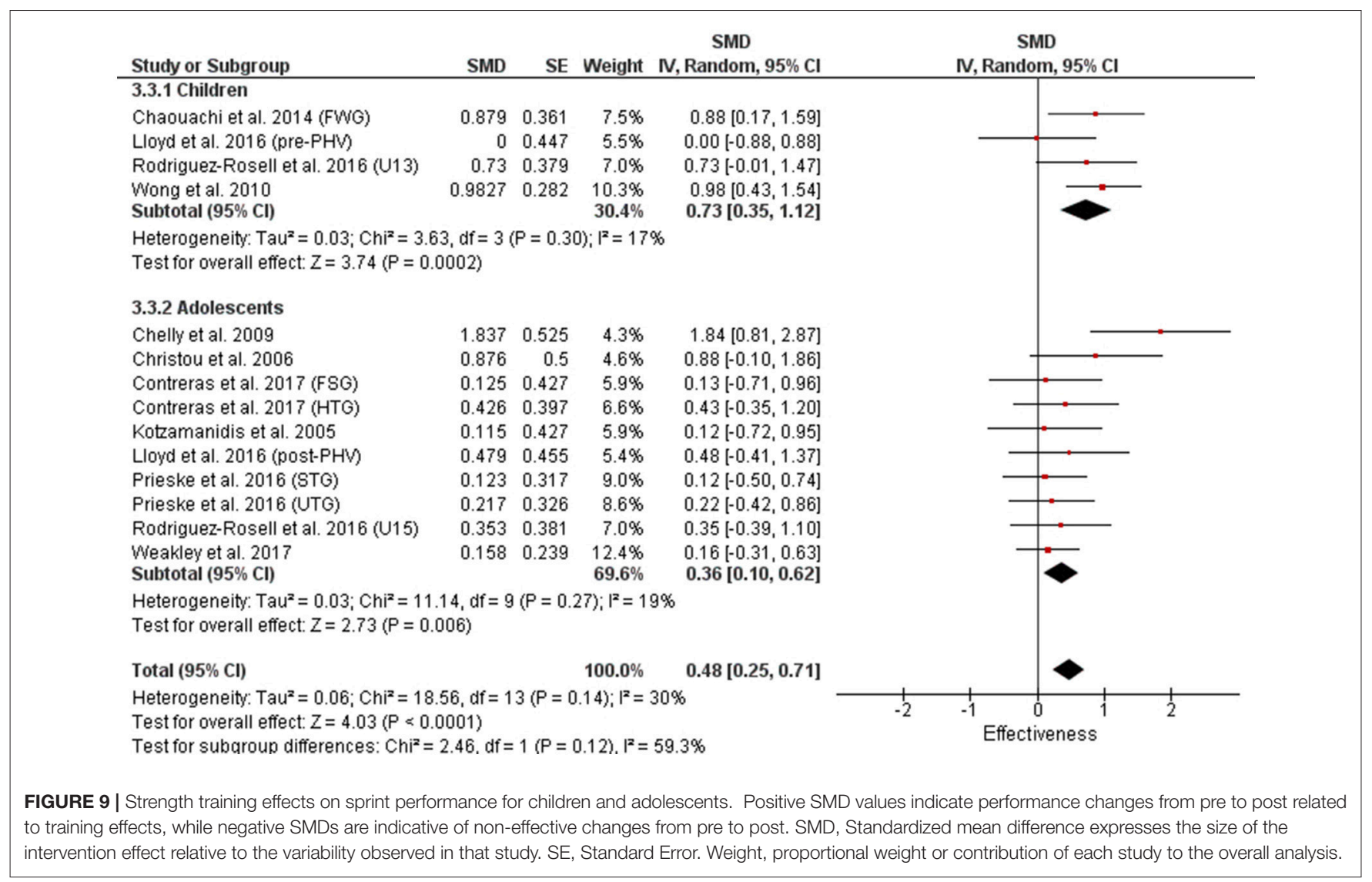

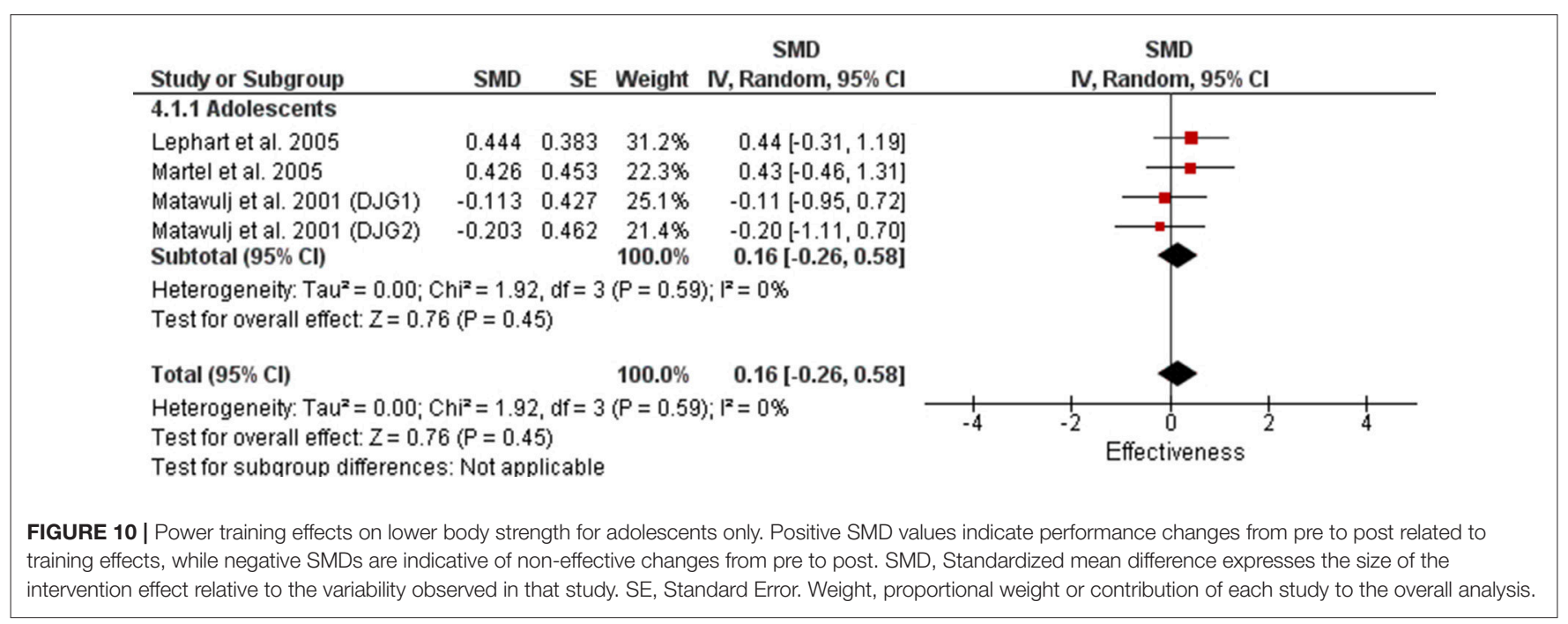

A limitation of this meta-analysis is that the involved studies investigated relatively healthy and athletic populations. Future studies should also focus on populations with risk factors. Furthermore, appropriate age or maturation matched power and plyometric training intensities, volumes, durations, frequencies and other factors (e.g., What is the optimal platform height for drop jumps with different youth maturational levels?
With the appropriate intensity established, what would be the appropriate volume of power training for each session or each week/cycle?) should be investigated to obtain the greatest benefits.

In conclusion, there was modest evidence for the effect of power training specificity upon power measures (small to moderate magnitudes of change). Plausibly due to the greater 


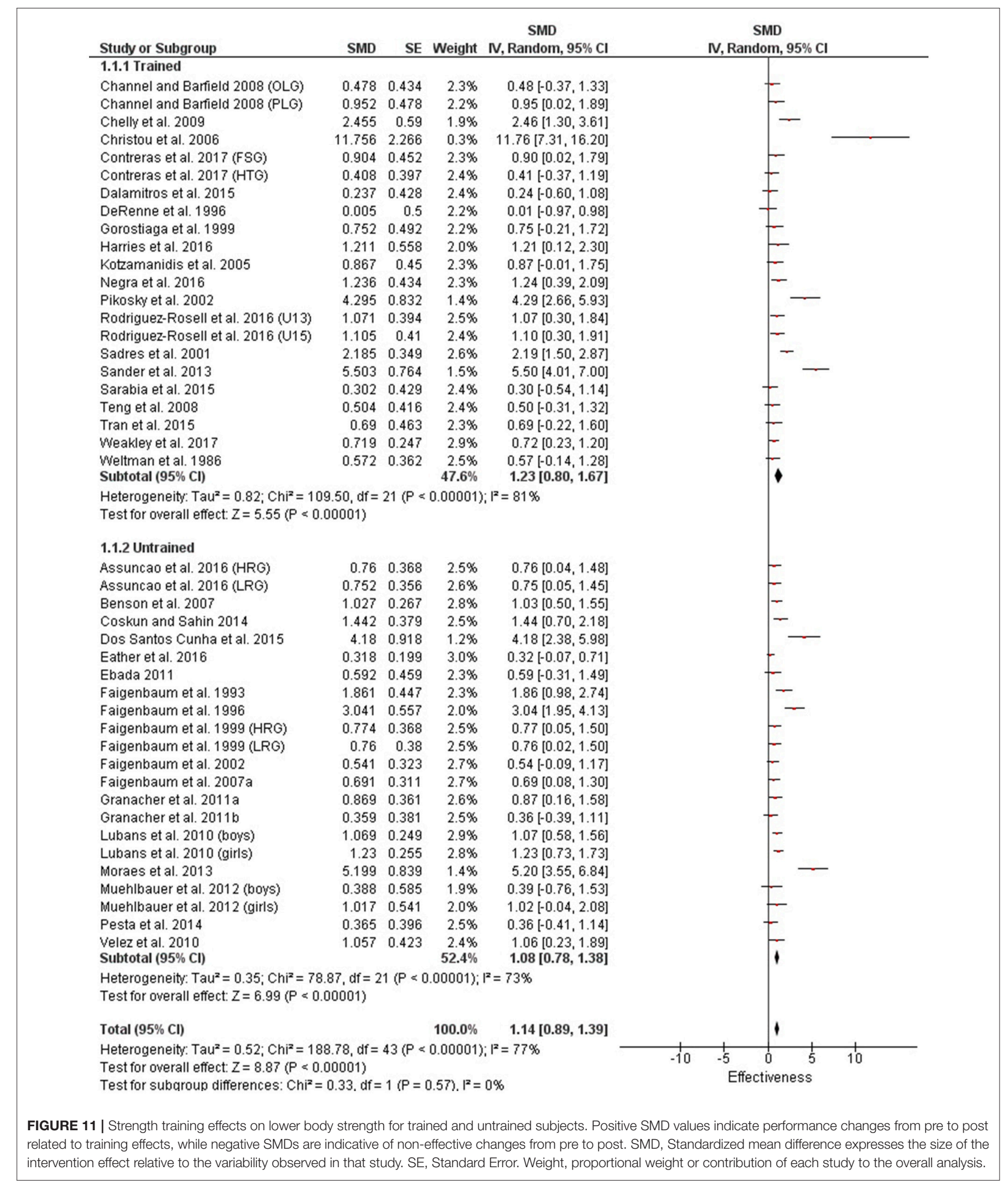

reaction forces with sprinting, there was no power training specific advantage with sprint results. On the contrary, strength training provided greater sprint training benefits likely due to the development of greater strength allowing the individuals to 


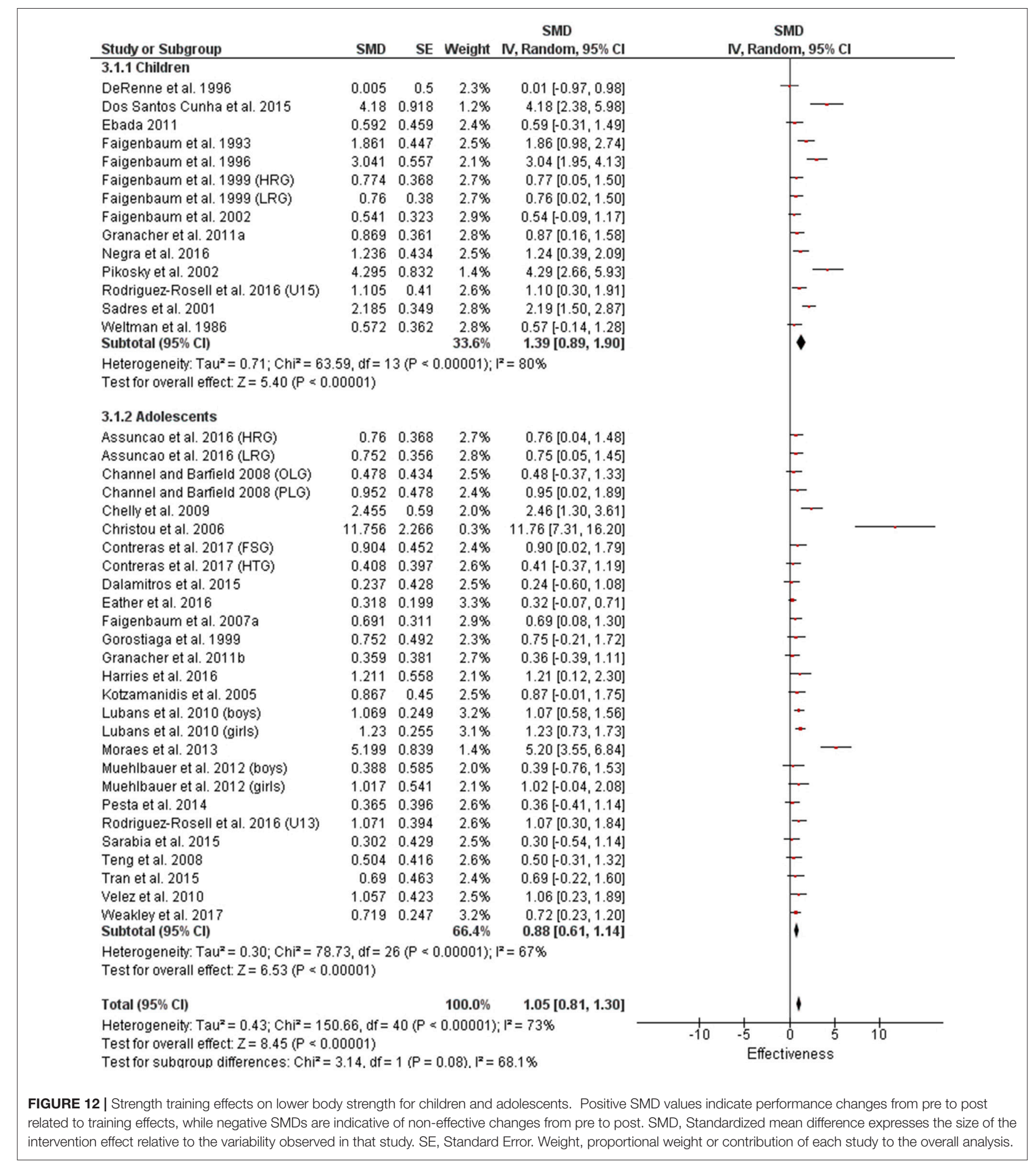

absorb and react to the ground reaction forces more efficiently to optimize the SSC mechanical and reflexive advantages. Strength training provided the greatest training specific results in youth with consistently large magnitude improvements in lower body strength across trained, vs. untrained, as well as with children vs. adolescents. In addition, untrained youth with their lower baseline of physical capacities (untapped training potentials), immature motor learning (Payne and Isaacs, 2005; Behm et al., 
2010b; Behringer et al., 2011; Hopper et al., 2017) and possibly due to their lack of experience tend to experience greater training benefits for power and sprint measures than trained youth. Based on these findings, resistance training for youth should initially emphasize strength training methods. Prior research has also demonstrated the importance of introducing balance training early in the training process (Behm et al., 2008; Hammami et al., 2016b). Plyometric training can also be included but this training should emphasize lower amplitude movements with low to moderate reaction forces (Behm et al., 2008). Proper form, balance and motor control should be first emphasized before presenting the individual with high reaction forces. As indicated

\section{REFERENCES}

Aagaard, P., Simonsen, E. B., Andersen, J. L., Magnusson, P., and Dyhre-Poulsen, P. (2002). Increased rate of force development and neural drive of human skeletal muscle following resistance training. J. Appl. Physiol. 93, 1318-1326. doi: 10.1152/japplphysiol.00283.2002

Alves, A. R., Marta, C. C., Neiva, H. P., Izquierdo, M., and Marques, M. C. (2016). Concurrent training in prepubescent children: the effects of 8 weeks of strength and aerobic training on explosive strength and V[Combining Dot Above]O2max. J. Strength Cond. Res. 30, 2019-2032. doi: 10.1519/JSC.0000000000001294

American College of Sports Medicine (2006). ACSM's Guidelines for Exercise Testing and Prescription. Philadelphia, PA: Lippincott, Williams and Wilkins Publishers.

Anderson, K., and Behm, D. G. (2005). The impact of instability resistance training on balance and stability. Sports Med. 35, 43-53. doi: 10.2165/00007256-200535010-00004

Arabatzi, F. (2016). Adaptations in movement performance after plyometric training on mini-trampoline in children. J. Sports Med. Phys. Fitness. [Epub ahead of print].

Assuncao, A. R., Bottaro, M., Ferreira-Junior, J. B., Izquierdo, M., Cadore, E. L., and Gentil, P. (2016). The chronic effects of low- and high-intensity resistance training on muscular fitness in adolescents. PLoS ONE 11:e0160650. doi: 10. 1371/journal.pone. 0160650

Attene, G., Iuliano, E., Di Cagno, A., Calcagno, G., Moalla, W., Aquino, G., et al. (2015). Improving neuromuscular performance in young basketball players: plyometric vs. technique training. J. Sports Med. Phys. Fitness 55, 1-8.

Avela, J., Finni, J., and Komi, P. V. (2006). Excitability of the soleus reflex arc during intensive stretch-shortening cycle exercise in two power-trained athlete groups. Eur. J. Appl. Physiol. 97, 486-493. doi: 10.1007/s00421-0060209-6

Behm, D. G. (1988). Surgical tubing for sport and velocity specific training. Nat. Strength Cond. Assoc. J. 10, 66-70.

Behm, D. G. (1993). Plyometric training for squash. Nat. Strength Cond. Assoc. J. $14,26-28$

Behm, D. G. (1995). Neuromuscular implications and applications of resistance training. J. Strength Cond. Res. 9, 264-274. doi: 10.1519/00124278-19951100 0-00014

Behm, D. G., Drinkwater, E. J., Willardson, J. M., and Cowley, P. M. (2010a). The use of instability to train the core musculature. Appl. Physiol. Nutr. Metab. 35, 91-108. doi: 10.1139/H09-127

Behm, D. G., Drinkwater, E. J., Willardson, J. M., Cowley, P. M., and Canadian Society for Exercise, P. (2010b). Canadian society for exercise physiology position stand: the use of instability to train the core in athletic and nonathletic conditioning. Appl. Physiol. Nutr. Metab. 35, 109-112. doi: 10.1139/H09-128

Behm, D. G., Faigenbaum, A. D., Falk, B., and Klentrou, P. (2008). Canadian Society for Exercise Physiology position paper: resistance training in children and adolescents. Appl. Physiol. Nutr. Metab. 33, 547-561. doi: 10.1139/H08-020

Behm, D. G., and Sale, D. G. (1993). Velocity specificity of resistance training. Sports Med. 15, 374-388. doi: 10.2165/00007256-199315060-00003 in the Canadian Society for Exercise Physiology position stand (Behm et al., 2008), plyometric training and other forms of power training (e.g., Olympic weight lifting) are not intended to be stand-alone exercise programs, the best approach is to incorporate properly supervised and progressive power training into a well-rounded program that also includes other types of strength and conditioning.

\section{AUTHOR CONTRIBUTIONS}

All authors listed have made a substantial, direct and intellectual contribution to the work, and approved it for publication.

Behm, D. G., Wahl, M. J., Button, D. C., Power, K. E., and Anderson, K. G. (2005). Relationship between hockey skating speed and selected performance measures. J. Strength Cond. Res. 19, 326-331. doi: 10.1519/00124278-20050500 0-00015

Behringer, M., Vom Heede, A., Matthews, M., and Mester, J. (2011). Effects of strength training on motor performance skills in children and adolescents: a meta-analysis. Pediat. Exerc. Sci. 23, 186-206. doi: 10.1123/pes.23.2.186

Benson, A. C., Torode, M. E., and Fiatarone Singh, M. A. (2007). A rationale and method for high-intensity progressive resistance training with children and adolescents. Contemp. Clin. Trials 28, 442-450. doi: 10.1016/j.cct.2006.11.004

Blimkie, C. J. (1993). Resistance traing during preadolescence. Sports Med. 15, 389-407. doi: 10.2165/00007256-199315060-00004

Blimkie, C. J. R. (1989). Effects of 10 weeks of resistance training on strength development in prepubertal boys. Sports Sci. 19, 105-114.

Blimkie, C. J. R. (1992). Resistance training during pre-and early puberty: efficacy, trainability, mechanisms, and persitence. Can. J. Sport Sci. 17, 264-279.

Borges, J. H., Conceição, M. S., Vechin, F. C., Pascoal, E. H. F., Silva, R. P., and Borin, J. P. (2016). The effects of resisted sprint vs. plyometric training on sprint performance and repeated sprint ability during the final weeks of the youth soccer season. Sci. Sports 31, 101-105. doi: 10.1016/j.scispo.2015.10.004

Bosco, C., Tarkka, I., and Komi, P. V. (1982a). Effect of elastic energy and myoelectrical potentiation of triceps surae during stretch-shortening cycle exercise. Int. J. Sports Med. 3, 137-140. doi: 10.1055/s-2008-1026076

Bosco, C., Viitasalo, J. T., Komi, P. V., and Luhtanen, P. (1982b). Combined effect of elastic energy and myoelectrical potentiation during stretch-shortening cycle exercise. Acta Physiol. Scand. 114, 557-565. doi: 10.1111/j.1748-1716.1982.tb07024.x

Brown, M. E., Mayhew, J. L., and Boleach, L. W. (1986). Effect of plyometric training on vertical jump performance in high school basketball players. $J$. Sports Med. Phys. Fitness 26, 1-4.

Buchheit, M., Mendez-Villanueva, A., Delhomel, G., Brughelli, M., and Ahmaidi, S. (2010). Improving repeated sprint ability in young elite soccer players: repeated shuttle sprints vs. explosive strength training. J. Strength Cond. Res. 24, 2715-2722. doi: 10.1519/JSC.0b013e3181bf0223

Cappa, D. F., and Behm, D. G. (2011). Training specificity of hurdle vs. countermovement jump training. J. Strength Cond. Res. 25, 2715-2729. doi: 10.1519/JSC.0b013e318208d43c

Cappa, D. F., and Behm, D. G. (2013). Neuromuscular characteristics of drop and hurdle jumps with different types of landings. J. Strength Cond. Res. 27, 3011-3020. doi: 10.1519/JSC.0b013e31828c28b3

Cavagna, G. A., Dusman, B., and Margaria, R. (1968). Positive work done by a previously stretched muscle. J. Appl. Physiol. 24, 21-32.

Chaabene, H., and Negra, Y. (2017). The effect of plyometric training volume in prepubertal male soccer players' athletic performance. Int. J. Sports Physiol. Perform. doi: 10.1123/ijspp.2016-0372. [Epub ahead of print].

Channell, B. T., and Barfield, J. P. (2008). Effect of Olympic and traditional resistance training on vertical jump improvement in high school boys. J. Strength Cond. Res. 22, 1522-1527. doi: 10.1519/JSC.0b013e318181a3d0

Chaouachi, A., Hammami, R., Kaabi, S., Chamari, K., Drinkwater, E. J. and Behm, D. G. (2014). Olympic weightlifting and plyometric training 
with children provides similar or greater performance improvements than traditional resistance training. J. Strength Cond. Res. 28, 1483-1496. doi: 10.1519/JSC.0000000000000305

Chelly, M. S., Fathloun, M., Cherif, N., Ben Amar, M., Tabka, Z., and Van Praagh, E. (2009). Effects of a back squat training program on leg power, jump, and sprint performances in junior soccer players. J. Strength Cond. Res. 23, 2241-2249. doi: 10.1519/JSC.0b013e3181b86c40

Chelly, M. S., Hermassi, S., and Shephard, R. J. (2015). Effects of in-season short-term plyometric training program on sprint and jump performance of young male track athletes. J. Strength Cond. Res. 29, 2128-2136. doi: 10.1519/JSC.0000000000000860

Christou, M., Smilios, I., Sotiropoulos, K., Volaklis, K., Pilianidis, T., and Tokmakidis, S. P. (2006). Effects of resistance training on the physical capacities of adolescent soccer players. J. Strength Cond. Res. 20, 783-791. doi: 10.1519/00124278-200611000-00010

Cohen, J. (1988). Statistical Power Analysis for the Behavioural Sciences. Hillside, NJ: L. Erbraum Associates.

Contreras, B., Vigotsky, A. D., Schoenfeld, B. J., Beardsley, C., McMaster, D. T., Reyneke, J. H., et al. (2017). Effects of a six-week hip thrust vs. front squat resistance training program on performance in adolescent males: a randomized controlled trial. J. Strength Cond. Res. 31, 999-1008. doi: 10.1519/JSC.0000000000001510

Cormie, P., McCaulley, G. O., and McBride, J. M. (2007). Power versus strengthpower jump squat training: influence on the load-power relationship. Med. Sci. Sports Exerc. 39, 996-1003. doi: 10.1097/mss.0b013e3180 $408 \mathrm{e} 0 \mathrm{c}$

Cormie, P., McGuigan, M. R., and Newton, R. U. (2010). Changes in the eccentric phase contribute to improved stretch-shorten cycle performance after training. Med. Sci. Sports Exerc. 42, 1731-1744. doi: 10.1249/MSS.0b013e3181d392e8

Coskun, A., and Sahin, G. (2014). Two different strength training and untrained period effects in children. J. Phys. Educ. Sport 14, 42-46. doi: 10.7752/jpes.2014. 01007

Cossor, J. M., Blanksby, B. A., and Elliott, B. C. (1999). The influence of plyometric training on the freestyle tumble turn. J. Sci. Med. Sport 2, 106-116. doi: 10.1016/S1440-2440(99)80190-X

Cronin, J., and Sleivert, G. (2005). Challenges in understanding the influence of maximal power training on improving athletic performance. Sports Med. 35, 213-234. doi: 10.2165/00007256-200535030-00003

Dalamitros, A. A., Manou, V., Christoulas, K., and Kellis, S. (2015). Knee muscles isokinetic evaluation after a six-month regular combined swim and dry-land strength training period in adolescent competitive swimmers. J. Hum. Kinet. 49, 195-200. doi: 10.1515/hukin-2015-0121

de Hoyo, M., Gonzalo-Skok, O., Sanudo, B., Carrascal, C., Plaza-Armas, J. R., Camacho-Candil, F., et al. (2016). Comparative effects of in-season fullback squat, resisted sprint training, and plyometric training on explosive performance in U-19 elite soccer players. J. Strength Cond. Res. 30, 368-377. doi: 10.1519/JSC.0000000000001094

DeRenne, C., Hetzler, R. K., Buxton, B. P., and Ho, K. W. (1996). Effects of training frequency on strength maintenance in pubescent baseball players. J. Strength Cond. Res. 10, 8-14. doi: 10.1519/00124278-199602000-00002

Diallo, O., Dore, E., Duche, P., and Van Praagh, E. (2001). Effects of plyometric training followed by a reduced training programme on physical performance in prepubescent soccer players. J. Sports Med. Phys. Fitness 41, 342-348.

Dintiman, G., and Ward, B. (2003). Sport Speed. Windsor, ON: Human Kinetics.

Dorgo, S., King, G. A., Candelaria, N. G., Bader, J. O., Brickey, G. D., and Adams, C. E. (2009). Effects of manual resistance training on fitness in adolescents. J. Strength Cond. Res. 23, 2287-2294. doi: 10.1519/JSC.0b013e3181 $\mathrm{b} 8 \mathrm{~d} 42 \mathrm{a}$

dos Santos Cunha, G., Santanna, M. M., Cadore, E. L., Oliveira, N. L., Santos, C. B., Pinto, R. S., et al. (2015). Physiological adaptations to resisitance training in prepubertal boys. Res. Q. Exerc. Sport 86, 172-181. doi: 10.1080/02701367.2014.982782

Drinkwater, E. J., Lawton, T. W., Lindsell, R. P., Pyne, D. B., Hunt, P. H., and McKenna, M. J. (2005). Training leading to repetition failure enhances bench press strength gains in elite junior athletes. J. Strength Cond. Res. 19, 382-388. doi: 10.1519/R-15224.1
Drinkwater, E. J., Pritchett, E. J., and Behm, D. G. (2007). Effect of instability and resistance on unintentional squat-lifting kinetics. Int. J. Sports Physiol. Perform. 2, 400-413. doi: 10.1123/ijspp.2.4.400

Eather, N., Morgan, P. J., and Lubans, D. R. (2016). Improving health-related fitness in adolescents: the CrossFit Teens randomised controlled trial. J. Sports Sci. 34, 209-223. doi: 10.1080/02640414.2015.1045925

Ebada, K. A. (2011). The effect of a training program on the development of the maximal strength for weightlifting beginner's performance. Selcuk Univ. J. Phys. Educ. Sport Sci. 13, 281-290.

Ettema, G. J., van Soest, A. J., and Huijing, P. A. (1990). The role of series elastic structures in prestretch-induced work enhancement during isotonic and isokinetic contractions. J. Exp. Biol. 154, 121-136.

Faigenbaum, A. D. (2006). Resistance training for children and adolescents: are there health outcomes? Sports Med. 44, 1209-1223. doi: $10.1177 / 1559827606296814$

Faigenbaum, A. D., Bush, J. A., McLoone, R. P., Kreckel, M. C., Farrell, A., Ratamess, N. A., et al. (2015). Benefits of strength and skill-based training during primary school physical education. J. Strength Cond. Res. 29, 1255-1262. doi: 10.1519/JSC.0000000000000812

Faigenbaum, A. D., Kraemer, W. J., Blimkie, C. J., Jeffreys, I., Micheli, L. J., Nitka, M., et al. (2009). Youth resistance training: updated position statement paper from the national strength and conditioning association. J. Strength Cond. Res. 23(5 Suppl.), S60-S79. doi: 10.1519/JSC.0b013e31819df407

Faigenbaum, A. D., Kraemer, W. J., Cahill, B., Chandler, J., Dziados, J., Elfrink, L. D., et al. (1996). Youth resistance training: position statement paper and literature review. Strength Cond. J. 18, 62-76. doi: 10.1519/1073-6840(1996)018<0062:YRTPSP > 2.3.CO;2

Faigenbaum, A. D., Loud, R. L., O'Connell, J., Glover, S., and Westcott, W. L. (2001). Effects of different resistance training protocols on upper-body strength and endurance development in children. J. Strength Cond. Res. 15, 459-465. doi: 10.1519/00124278-200111000-00010

Faigenbaum, A. D., McFarland, J. E., Johnson, L., Kang, J., Bloom, J., Ratamess, N. A., et al. (2007a). Preliminary evaluation of an after-school resistance training program for improving physical fitness in middle school-age boys. Percept. Mot. Skills 104, 407-415. doi: 10.2466/pms.104.2.407-415

Faigenbaum, A. D., McFarland, J. E., and Keiper, F. B. (2007b). Effects of a short term plyometric and resistance training program on fitness performance in boys aged 12 to 15 years. J. Sports Sci. Med. 6, 519-525.

Faigenbaum, A. D., Milliken, L. A., Loud, R. L., Burak, B. T., Doherty, C. L., and Westcott, W. L. (2002). Comparison of 1 and 2 days per week of strength training in children. Res. Q. Exerc. Sport 73, 416-424. doi: 10.1080/02701367.2002.10609041

Faigenbaum, A. D., Myer, G. D., Farrell, A., Radler, T., Fabiano, M., Kang, J., et al. (2014). Integrative neuromuscular training and sex-specific fitness performance in 7-year-old children: an exploratory investigation. J. Athl. Train 49, 145-153. doi: 10.4085/1062-6050-49.1.08

Faigenbaum, A. D., Westcott, W. L., Loud, R. L., and Long, C. (1999). The effects of different resistance training protocols on muscular strength and endurance development in children. Pediatrics 104, e5-e15. doi: 10.1542/peds.104.1.e5

Faigenbaum, A. D., Wayne, L., Michelli, L. J., and Zaichkowsky, L. D. (1996). The effects of strength training and detraining on children. J. Strength Cond. Res. 10, $109-114$

Faigenbaum, A. D., Zaichkowsky, L., Westcott, W., Michelli, L., and Fehlandt, A. (1993). The effects of twice per week strength training program on children. Pediatr. Exerc. Sci. 5, 339-346. doi: 10.1123/pes.5.4.339

Faigenbaum, A., and Kang, J. (2005). Youth strength training: facts, fallacies and program design considerations. Am. Coll. Sports Med. Cert. News 15, 5-7.

Falk, B., and Dotan, R. (2006). Child-adult differences in the recovery from high-intensity exercise. Exerc. Sport Sci. Rev. 34, 107-112. doi: 10.1249/00003677-200607000-00004

Falk, B., and Eliakim, A. (2003). Resistance training, skeletal muscle and growth. Pediatr. Endocrinol. Rev. 1, 120-127.

Falk, B., and Mor, G. (1996). The effects of resistance and martial arts training in 6- to 8-year old boys. Pediatr. Exerc. Sci. 8, 48-56. doi: 10.1123/pes.8.1.48

Falk, B., and Tenenbaum, G. (1996). The effectiveness of resistance training in children. Sports Med. 22, 176-186. doi: 10.2165/00007256-19962203000004 
Fernandez-Fernandez, J., de Villarreal, E. S., Sanz-Rivas, D., and Moya, M. (2016). The effects of 8-week plyometric training on physical performance in young tennis players. Pediatr. Exerc. Sci. 28, 77-86. doi: 10.1123/pes.2015-0019

Ferrete, C., Requena, B., Suarez-Arrones, L., and de Villarreal, E. S. (2014). Effect of strength and high-intensity training on jumping, sprinting, and intermittent endurance performance in prepubertal soccer players. J. Strength Cond. Res. 28, 413-422. doi: 10.1519/JSC.0b013e31829b2222

Flanagan, S. P., Laubach, L. L., De Marco, G. M. Jr., Alvarez, C., Borchers, S., Dressman, E., et al. (2002). Effects of two different strength training modes on motor performance in children. Res. Q. Exerc. Sport 73, 340-344. doi: 10.1080/02701367.2002.10609029

Funato, K., Fukunaga, T., Asami, T., and Ikeda, S. (1986). Strength training for prepubescent boys and girls. J. Pediat. Orthop. 6, 9-19.

Golan, R., Falk, B., Hoffman, J., Hochberg, Z., Ben-Sira, D., and Barak, Y. (1998). Resistance training for children and adolescents. Position statement by the International Federation of Sports Medicine (FIMS). Position Statement Int. Feder. Sports Med. 265-270. Available online at: http://www.fims.org

Gonzalez-Badillo, J. J., Pareja-Blanco, F., Rodriguez-Rosell, D., Abad-Herencia, J. L., Del Ojo-Lopez, J. J., and Sanchez-Medina, L. (2015). Effects of velocity-based resistance training on young soccer players of different ages. J. Strength Cond. Res. 29, 1329-1338. doi: 10.1519/JSC.0000000000000764

Gorostiaga, E. M., Izquierdo, M., Iturralde, P., Ruesta, M., and Ibanez, J. (1999). Effects of heavy resistance training on maximal and explosive force production, endurance and serum hormones in adolescent handball players. Eur. J. Appl. Physiol. Occup. Physiol. 80, 485-493. doi: 10.1007/s004210050622

Granacher, U., Goesele, A., Roggo, K., Wischer, T., Fischer, S., Zuerny, C., et al. (2011a). Effects and mechanisms of strength training in children. Int. J. Sports Med. 32, 357-364. doi: 10.1055/s-0031-1271677

Granacher, U., Gollhofer, A., and Kriemler, S. (2010). Effects of balance training on postural sway, leg extensor strength, and jumping height in adolescents. Res. Q. Exerc. Sport. 81, 245-251. doi: 10.1080/02701367.2010.10599672

Granacher, U., Lesinski, M., Busch, D., Muehlbauer, T., Prieske, O., Puta, C., et al. (2016). Effects of resistance training in youth athletes on muscular fitness and athletic performance: a conceptual model for long-term athlete development. Front. Physiol. 7:164. doi: 10.3389/fphys.2016.00164

Granacher, U., Muehlbauer, T., Doerflinger, B., Strohmeier, R., and Gollhofer, A. (2011b). Promoting strength and balance in adolescents during physical education: effects of a short-term resistance training. J. Strength Cond. Res. 25, 940-949. doi: 10.1519/JSC.0b013e3181c7bb1e

Granacher, U., Prieske, O., Majewski, M., Busch, D., and Muehlbauer, T. (2015). The role of instability with plyometric training in sub-elite adolescent soccer players. Int. J. Sports Med. 36, 386-394. doi: 10.1055/s-0034-1395519

Granacher, U., Schellbach, J., Klein, K., Prieske, O., Baeyens, J. P., and Muehlbauer, T. (2014). Effects of core strength training using stable versus unstable surfaces on physical fitness in adolescents: a randomized controlled trial. BMC Sports Sci. Med. Rehab. 6:40. doi: 10.1186/2052-1847-6-40

Hall, E., Bishop, D. C., and Gee, T. I. (2016). Effect of plyometric training on handspring vault performance and functional power in youth female gymnasts. PLoS ONE 11:e0148790. doi: 10.1371/journal.pone.0148790

Hammami, R., Chaouachi, A., Makhlouf, I., Granacher, U., and Behm, D. G. (2016a). Associations between balance and muscle strength, power performance in male youth athletes of different maturity status. Pediatr. Exerc. Sci. 28, 521-534. doi: 10.1123/pes.2015-0231

Hammami, R., Granacher, U., Makhlouf, I., Behm, D. G., and Chaouachi, A. (2016b). Sequencing effects of balance and plyometric training on physical performance in youth soccer athletes. J. Strength Cond. Res. 30, 3278-3289. doi: 10.1519/JSC.0000000000001425

Harries, S. K., Lubans, D. R., and Callister, R. (2016). Comparison of resistance training progression models on maximal strength in sub-elite adolescent rugby union players. J. Sci. Med. Sport 19, 163-169. doi: 10.1016/j.jsams.2015.01.007

Hass, C. J., Feigenbaum, M. S., and Franklin, B. A. (2001). Prescription of resistance training for healthy populations. Sports Med. 31, 953-964. doi: 10.2165/00007256-200131140-00001

Hedges, L. V. (1985). Statistical Methods for Meta-Analysis. Orlando, FL: Academic Press.

Hettinger, T. (1958). Muscle training in relation to age and sex. Int. Z. Angew. Physiol. 17, 371-377.
Hewett, T. E., Stroupe, A. L., Nance, T. A., and Noyes, F. R. (1996). Plyometric training in female athletes. Decreased impact forces and increased hamstring torques. Am. J. Sports Med. 24, 765-773. doi: 10.1177/036354659602400611

Hopper, A., Haff, E. E., Barley, O. R., Joyce, C., Lloyd, R. S., and Haff, G. G. (2017). Neuromuscular training improves movement competency and physical performance measures in 11-13-year-old female netball athletes. J. Strength Cond. Res. 31, 1165-1176. doi: 10.1519/JSC.0000000000001794

Ignjatovic, A., Radovanovic, D., Stankovic, R., Markovic, Z., and Kocic, J. (2011). Influence of resistance training on cardiorespiratory endurance and muscle power and strength in young athletes. Acta Physiol. Hung. 98, 305-312. doi: 10.1556/APhysiol.98.2011.3.7

Johnson, B. A., Salzberg, C. L., and Stevenson, D. A. (2011). A systematic review: plyometric training programs for young children. J. Strength Cond. Res. 25, 2623-2633. doi: 10.1519/JSC.0b013e318204caa0

King, J. A., and Cipriani, D. J. (2010). Comparing preseason frontal and sagittal plane plyometric programs on vertical jump height in high-school basketball players. J. Strength Cond. Res. 24, 2109-2114. doi: 10.1519/JSC.0b013e3181e347d1

Komi, P. V. (1986). The Stretch-Shortening Cycle and Human Power Output. Champaign, IL: Human Kinetics Champaign.

Kotzamanidis, C. (2006). Effect of plyometric training on running performance and vertical jumping in prepubertal boys. J. Strength Cond. Res. 20, 441-445. doi: 10.1519/00124278-200605000-00034

Kotzamanidis, C., Chatzopoulos, D., Michailidis, C., Papaiakovou, G., and Patikas, D. (2005). The effect of a combined high-intensity strength and speed training program on the running and jumping ability of soccer players. J. Strength Cond. Res. 19, 369-375. doi: 10.1519/R-14944.1

Lephart, S. M., Abt, J. P., Ferris, C. M., Sell, T. C., Nagai, T., Byers, J. B., et al. (2005). Neuromuscular and biomechanical characteristic changes in high school athletes: a plyometric versus basic resistance program. Br. J. Sports Med. 39, 932-938. doi: 10.1136/bjsm.2005.019083

Lichtwark, G. A., and Wilson, A. M. (2005). Effects of series elasticity and activation conditions on muscle power output and efficiency. J. Exp. Biol. 208, 2845-2853. doi: $10.1242 /$ jeb.01710

Lillegard, W. A., Brown, E. W., Wilson, D. J., Henderson, R., and Lewis, E. (1997). Efficacy of strength training in prepubescent to early postpubescent males and females: effects of gender and maturity. Pediatr. Rehabil. 1, 147-157. doi: 10.3109/17518429709167353

Lloyd, R. S., Oliver, J. L., Hughes, M. G., and Williams, C. A. (2012). The effects of 4-weeks of plyometric training on reactive strength index and leg stiffness in male youths. J. Strength Cond. Res. 26, 2812-2819. doi: 10.1519/JSC.0b013e318242d2ec

Lloyd, R. S., Radnor, J. M., De Ste Croix, M. B., Cronin, J. B., and Oliver, J. L. (2016). Changes in sprint and jump performances after traditional, plyometric, and combined resistance training in male youth pre- and post-peak height velocity. J. Strength Cond. Res. 30, 1239-1247. doi: 10.1519/JSC.0000000000001216

Lubans, D. R., Sheaman, C., and Callister, R. (2010). Exercise adherence and intervention effects of two school-based resistance training programs for adolescents. Prev. Med. 50, 56-62. doi: 10.1016/j.ypmed.2009.12.003

Malina, R. (2006). Weight training in youth. Growth, maturation and safety: an evidence based review. Clin. J. Sports Med. 16, 478-487. doi: 10.1097/01.jsm.0000248843.31874.be

Marginson, V., Rowlands, A. V., Gleeson, N. P., and Eston, R. G. (2005). Comparison of the symptons of exercise-induced muscle damage after an initial and repeated bout of plyometric exercise in men and boys. J. Appl. Physiol. 99, 1174-1181. doi: 10.1152/japplphysiol.01193.2004

Marques, M. C., Pereira, A., Reis, I. G., and van den Tillaar, R. (2013). Does an inseason 6-week combined sprint and jump training program improve strengthspeed abilities and kicking performance in young soccer players? J. Hum. Kinet. 39, 157-166. doi: 10.2478/hukin-2013-0078

Marta, C. C., Marinho, D. A., Izquierdo, M., and Marques, M. C. (2014). Differentiating maturational influence on training-induced strength and endurance adaptations in prepubescent children. Am. J. Hum. Biol. 26, 469-475. doi: 10.1002/ajhb.22549

Martel, G. F., Harmer, M. L., Logan, J. M., and Parker, C. B. (2005). Aquatic plyometric training increases vertical jump in female volleyball players. Med. Sci. Sports Exerc. 37, 1814-1819. doi: 10.1249/01.mss.0000184289.87574.60 
Matavulj, D., Kukolj, M., Ugarkovic, D., Tihanyi, J., and Jaric, S. (2001). Effects of plyometric training on jumping performance in junior basketball players. J. Sports Med. Phys. Fitness 41, 159-164.

McCarthy, J. P., Wood, D. S., Bolding, M. S., Roy, J. L., and Hunter, G. R. (2012). Potentiation of concentric force and acceleration only occurs early during the stretch-shortening cycle. J. Strength Cond. Res. 26, 2345-2355. doi: 10.1519/JSC.0b013e3182606cc5

McCormick, B. T., Hannon, J. C., Newton, M., Shultz, B., Detling, N., and Young, W. B. (2016). The effects of frontal- and sagittal-plane plyometrics on changeof-direction speed and power in adolescent female basketball players. Int. J. Sports Physiol. Perform. 11, 102-107. doi: 10.1123/ijspp.2015-0058

McNeely, E., and Armstrong, L. (2002). Strength training for children: a review and recommendations. Phys. Health Educ. J. 68, 1-6.

Mero, A., Komi, P. V., and Gregor, R. J. (1992). Biomechanics of sprint running. A review. Sports Med. 13, 376-392. doi: 10.2165/00007256-199213060-00002

Meylan, C., and Malatesta, D. (2009). Effects of in-season plyometric training within soccer practice on explosive actions of young players. J. Strength Cond. Res. 23, 2605-2613. doi: 10.1519/JSC.0b013e3181b1f330

Michailidis, Y., Fatouros, I. G., Primpa, E., Michailidis, C., Avloniti, A., Chatzinikolaou, A., et al. (2013). Plyometrics' trainability in preadolescent soccer athletes. J. Strength Cond. Res. 27, 38-49. doi: 10.1519/JSC.0b013e3182541ec6

Miyaguchi, K., and Demura, S. (2008). Relationships between muscle power output using the stretch-shortening cycle and eccentric maximum strength. J. Strength Cond. Res. 22, 1735-1741. doi: 10.1519/JSC.0b013e318182220a

Moore, S. D., Uhl, T. L., and Kibler, W. B. (2013). Improvements in shoulder endurance following a baseball-specific strengthening program in high school baseball players. Sports Health 5, 233-238. doi: 10.1177/1941738113477604

Moraes, E., Fleck, S. J., Ricardo Dias, M., and Simao, R. (2013). Effects on strength, power, and flexibility in adolescents of nonperiodized vs. daily nonlinear periodized weight training. J. Strength Cond. Res. 27, 3310-3321. doi: 10.1519/JSC.0b013e31828de8c3

Moran, J., Sandercock, G. R., Ramirez-Campillo, R., Todd, O., and Collison, P. D. A. (2016). Maturation-related effect of low-dose plyometric training on performance in youth hockey players. Pediatr. Exerc. Sci. 26, 1-24. doi: $10.1123 /$ pes.2016-0151

Muehlbauer, T., Gollhofer, A., and Granacher, U. (2012). Sex-related effects in strength training during adolescence: a pilot study. Percept. Mot. Skills 115, 953-968. doi: 10.2466/06.10.30.PMS.115.6.953-968

Murphy, J. R., Button, D. C., Chaouachi, A., and Behm, D. G. (2014). Prepubescent males are less susceptible to neuromuscular fatigue following resistance exercise. Eur. J. Appl. Physiol. 114, 825-835. doi: 10.1007/s00421-0132809-2

Negra, Y., Chaabene, H., Hammami, M., Hachana, Y., and Granacher, U. (2016). Effects of high-velocity resistance training on athletic performance in prepuberal male soccer athletes. J. Strength Cond. Res. 30, 3290-3297. doi: $10.1519 /$ JSC.0000000000001433

Noyes, F. R., Barber-Westin, S. D., Smith, S. T., Campbell, T., and Garrison, T. T. (2012). A training program to improve neuromuscular and performance indices in female high school basketball players. J. Strength Cond. Res. 26, 709-719. doi: 10.1519/JSC.0b013e318228194c

Noyes, F. R., Barber-Westin, S. D., Tutalo Smith, S. T., and Campbell, T. (2013). A training program to improve neuromuscular and performance indices in female high school soccer players. J. Strength Cond. Res. 27, 340-351. doi: 10.1519/JSC.0b013e31825423d9

Ozmun, J., Mikesky, A., and Paul Surburg, P. (1994). Neuromuscular adaptations following prepubescent strength training. Med. Sci. Sports Exerc. 26, 510-514. doi: 10.1249/00005768-199404000-00017

Payne, V. G., and Isaacs, L. D. (2005). Human Motor Development. A Lifespan Approach. Toronto, ON: McGraw Hill Publishers.

Payne, V. G., Morrow, J. R., Johnson, L., and Dalton, S. N. (1997). Resistance training in children and youth: a meta-analysis. Res. Q. Exerc. Sport 19, 80-88. doi: 10.1080/02701367.1997.10608869

Pereira, A., Costa, A. M., Santos, P., Figueiredo, T., and Joao, P. V. (2015). Training strategy of explosive strength in young female volleyball players. Medicina 51, 126-131. doi: 10.1016/j.medici.2015.03.004

Pesta, D., Thaler, A., Hoppel, F., Macek, C., Schocke, M., and Burtscher, M. (2014). Effects of a 10-week conventional strength training program on lower leg muscle performance in adolescent boys compared to adults. J. Sports Med. Phys. Fitness 54, 147-153.

Pfeiffer, R. D., and Francis, R. S. (1986). Effects of strength training on muscle development in prepubescent, pubescent, and postpubescent males. Phys. Sportsmed. 14, 134-143. doi: 10.1080/00913847.1986.117 09173

Piazza, M., Battaglia, C., Fiorilli, G., Innocenti, G., Iuliano, E., Aquino, G., et al. (2014). Effects of resistance training on jumping performance in pre-adolescent rhythmic gymnasts: a randomized controlled study. Ital. J. Anat. Embryol. 119, $10-19$.

Pikosky, M., Faigenbaum, A., Westcott, W., and Rodriguez, N. (2002). Effects of resistance training on protein utilization in healthy children. Med. Sci. Sports Exerc. 34, 820-827. doi: 10.1097/00005768-200205000-00015

Potdevin, F. J., Alberty, M. E., Chevutschi, A., Pelayo, P., and Sidney, M. C. (2011). Effects of a 6-week plyometric training program on performances in pubescent swimmers. J. Strength Cond. Res. 25, 80-86. doi: 10.1519/JSC.0b013e3181fef720

Prieske, O., Muehlbauer, T., Borde, R., Gube, M., Bruhn, S., Behm, D. G., et al. (2016). Neuromuscular and athletic performance following core strength training in elite youth soccer: role of instability. Scand. J. Med. Sci. Sports 26, 48-56. doi: 10.1111/sms. 12403

Radnor, J. M., Lloyd, R. S., and Oliver, J. L. (2017). Individual response to different forms of resistance training in school-aged boys. J. Strength Cond. Res. 31, 787-797. doi: 10.1519/JSC.0000000000001527

Ramirez-Campillo, R., Andrade, D. C., and Izquierdo, M. (2013). Effects of plyometric training volume and training surface on explosive strength. $J$. Strength Cond. Res. 27, 2714-2722. doi: 10.1519/JSC.0b013e318280c9e9

Ramírez-Campillo, R., Burgos, C. H., Henríquez-Olguín, C., Andrade, D. C., Martínez, C., Álvarez, C., et al. (2015c). Effect of unilateral, bilateral, and combined plyometric training on explosive and endurance performance of young soccer players. J. Strength Cond. Res. 29, 1317-1328. doi: 10.1519/JSC.0000000000000762

Ramirez-Campillo, R., Gallardo, F., Henriquez-Olguin, C., Meylan, C. M., Martinez, C., Alvarez, C., et al. (2015b). Effect of vertical, horizontal, and combined plyometric training on explosive, balance, and endurance performance of young soccer players. J. Strength Cond. Res. 29, 1784-1795. doi: 10.1519/JSC.0000000000000827

Ramirez-Campillo, R., Henriquez-Olguin, C., Burgos, C., Andrade, D. C., Zapata, D., Martinez, C., et al. (2015a). Effect of progressive volumebased overload during plyometric training on explosive and endurance performance in young soccer players. J. Strength Cond. Res. 29, 1884-1893. doi: 10.1519/JSC.0000000000000836

Ramirez-Campillo, R., Meylan, C., Álvarez, C., Henríquez-Olguín, C., Martínez, C., Cañas, R., et al. (2014). Effects of in-season lowvolume high-intensity plyometric training on explosive actions and endurance of young soccer players. J. Strength Cond. Res. 28, 1335-1342. doi: 10.1519/JSC.0000000000000284

Ramsay, J. A., Blimkie, C. J., Smith, K., Garner, S., MacDougall, J. D., and Sale, D. G. (1990). Strength training effects in prepubescent boys. Med. Sci. Sports Exerc. 22, 605-614. doi: 10.1249/00005768-199010000-00011

Ratel, S., Duche, P., and Williams, C. A. (2006). Muscle fatigue during high-intensity exercise in children. Sports Med. 36, 1031-1065. doi: 10.2165/00007256-200636120-00004

Ratel, S., Kluka, V., Vicencio, S. G., Jegu, A. G., Cardenoux, C., Morio, C., et al. (2015). Insights into the mechanisms of neuromuscular fatigue in boys and men. Med. Sci. Sports Exerc. 47, 2319-2328. doi: 10.1249/MSS.0000000000000697

Rhea, M. R., Peterson, M. D., Lunt, K. T., and Ayllon, F. N. (2008). The effectiveness of resisted jump training on the VertiMax in high school athletes. J. Strength Cond. Res. 22, 731-734. doi: 10.1519/JSC.0b013e3181660c59

Rians, C. B., Weltman, A., Cahill, B. R., Janney, C. A., Tippett, S. R., and Katch, F. I. (1987). Strength training for prepubescent males: is it safe? Am. J. Sports Med. 15, 483-489. doi: 10.1177/036354658701500510

Riviere, M., Louit, L., Strokosch, A., and Seitz, L. B. (2017). Variable resistance training promotes greater strength and power adaptations than traditional resistance training in elite youth rugby league players. J. Strength Cond. Res. 31, 947-955. doi: 10.1519/JSC.0000000000001574

Rodriguez-Rosell, D., Franco-Marquez, F., Pareja-Blanco, F., Mora-Custodio, R., Yanez-Garcia, J. M., Gonzalez-Suarez, J. M., et al. (2016). Effects of 6 weeks 
resistance training combined with plyometric and speed exercises on physical performance of pre-peak-height-velocity soccer players. Int. J. Sports Physiol. Perform. 11, 240-246. doi: 10.1123/ijspp.2015-0176

Rosas, F., Ramirez-Campillo, R., Diaz, D., Abad-Colil, F., Martinez-Salazar, C., Caniuqueo, A., et al. (2016). Jump training in youth soccer players: effects of haltere type handheld loading. Int. J. Sports Med. 37, 1060-1065. doi: 10.1055/s-0042-111046

Sadres, E., Eliakim, A., Constantini, N., Lidor, R., and Falk, B. (2001). The effect of long-term resistance training on anthropometric measures, muscle strength, and self concept in pre-pubertal boys. Pediatr. Exerc. Sci. 13, 357-372. doi: 10.1123 /pes.13.4.357

Sailors, M., and Berg, K. (1987). Comparison of responses to weight training in pubescent boys and men. J. Sports Med. Phys. Fitness 27, 30-37.

Sale, D. G. (1989). "Strength training in children," in Perspectives in Exercise Science and Sports Medicine, 2nd Edn., eds C. V. Gisolfi and D. R. Lamb (Carmel, IN: Benchmark Press), 99-163.

Sale, D. G., and MacDougall, J. D. (1981). Specificity in strength training: a review for the coach and athlete. Can. J. App. Sports Sci. 6, 87-92.

Sander, A., Keiner, M., Wirth, K., and Schmidtbleicher, D. (2013). Influence of a 2year strength training programme on power performance in elite youth soccer players. Eur. J. Sport Sci. 13, 445-451. doi: 10.1080/17461391.2012.742572

Santos, A. P., Marinho, D. A., Costa, A. M., Izquierdo, M., and Marques, M. C. (2012). The effects of concurrent resistance and endurance training follow a detraining period in elementary school students. J. Strength Cond. Res. 26, 1708-1716. doi: 10.1519/JSC.0b013e318234e872

Santos, E. J., and Janeira, M. A. (2011). The effects of plyometric training followed by detraining and reduced training periods on explosive strength in adolescent male basketball players. J. Strength Cond. Res. 25, 441-452. doi: 10.1519/JSC.0b013e3181b62be3

Santos, E. J., and Janeira, M. A. (2012). The effects of resistance training on explosive strength indicators in adolescent basketball players. J. Strength Cond. Res. 26, 2641-2647. doi: 10.1519/JSC.0b013e31823f8dd4

Sarabia, J. M., Fernandez-Fernandez, J., Juan-Recio, C., Hernandez-Davo, H., Urban, T., and Moya, M. (2015). Mechanical, hormonal and psychological effects of a non-failure short-term strength training program in young tennis players. J. Hum. Kinet. 45, 81-91. doi: 10.1515/hukin-2015-0009

Sewall, L., and Micheli, L. (1986). Strength training for children. J. Pediatr. Orthoped. 6, 143-146. doi: 10.1097/01241398-198603000-00004

Siegel, J. A., Camaione, D. N., and Manfredi, T. G. (1989). The effects of upper body resistance training on prepubescent children. Pediatr. Exerc. Sci. 1, 145-154. doi: 10.1123/pes.1.2.145

Skurvydas, A., and Brazaitis, M. (2010). Plyometric training does not affect central and peripheral muscle fatigue differently in prepubertal girls and boys. Pediatr. Exerc. Sci. 22, 547-556. doi: 10.1123/pes.22.4.547

Skurvydas, A., Brazaitis, M., Streckis, V., and Rudas, E. (2010). The effect of plyometric training on central and peripheral fatigue in boys. Int. J. Sports Med. 31, 451-457. doi: 10.1055/s-0030-1251991

Sohnlein, Q., Muller, E., and Stoggl, T. L. (2014). The effect of 16-week plyometric training on explosive actions in early to mid-puberty elite soccer players. $J$. Strength Cond. Res. 28, 2105-2114. doi: 10.1519/JSC.0000000000000387

Steele, J., Fisher, J. P., Assuncao, A. R., Bottaro, M., and Gentil, P. (2017). The role of volume-load in strength and absolute endurance adaptations in adolescent's performing high- or low-load resistance training. Appl. Physiol. Nutr. Metab. 42, 193-201. doi: 10.1139/apnm-2016-0418
Szymanski, D. J., Szymanski, J. M., Bradford, T. J., Schade, R. L., and Pascoe, D. D. (2007). Effect of twelve weeks of medicine ball training on high school baseball players. J. Strength Cond. Res. 21, 894-901. doi: 10.1519/00124278-200708000-00041

Teng, W. M., Chen, C. K., Ghosh, A. K., and Thimurayan, V. (2008). Effects of a resistance training programme on isokinetic peak torque and anaerobic power of 13-16 year old taekwondo athletes. Int. J. Sports Sci. Eng. 2, 111-121.

Thomas, K., French, D., and Hayes, P. R. (2009). The effect of two plyometric training techniques on muscular power and agility in youth soccer players. J. Strength Cond. Res. 23, 332-335. doi: 10.1519/JSC.0b013e3181 $83 \mathrm{a} 01 \mathrm{a}$

Tran, T. T., Nimphius, S., Lundgren, L., Secomb, J., Farley, O. R. L., Haff, G. G., et al. (2015). Effects of unstable and stable resistance training on strength, power, and sensorimotor abilities in adolescent surfers. Int. J. Sport Sci. Coach 10, 899-910. doi: 10.1260/1747-9541.10.5.899

Tsolakis, C. K., Vagenas, G. K., and Dessypris, A. G. (2004). Strength adaptations and hormonal responses to resistance training and detraining in preadolescent males. J. Strength Cond. Res. 18, 625-629. doi: 10.1519/00124278-200408000-00041

Velez, A., Golem, D. L., and Arent, S. M. (2010). The impact of a 12week resistance training program on strength, body composition, and selfconcept of Hispanic adolescents. J. Strength Cond. Res. 24, 1065-1073. doi: 10.1519/JSC.0b013e3181cc230a

Weakley, J., Till, K., Darrall-Jones, J., Roe, G., Phibbs, P., Read, D., et al. (2017). The influence of resistance training experience on the between-day reliability of commonly used strength measures in male youth athletes. J. Strength Cond. Res. doi: 10.1519/JSC.0000000000001883. [Epub ahead of print].

Webb, D. R. (1990). Strength training in children and adolescents. Sports Med. 37, 1187-1210. doi: 10.1016/s0031-3955(16)36983-8

Weltman, A., Janney, C., Rians, C. B., Strand, K., Berg, B., Tippitt, S., et al. (1986). The effects of hydraulic resistance strength training in pre-pubertal males. Med. Sci. Sports Exerc. 18, 629-638. doi: 10.1249/00005768-19861200000005

Witzke, K. A., and Snow, C. M. (2000). Effects of plyometric jump training on bone mass in adolescent girls. Med. Sci. Sports Exerc. 32, 1051-1057. doi: 10.1097/00005768-200006000-00003

Wong, P. L., Chamari, K., and Wisloff, U. (2010). Effects of 12-week onfield combined strength and power training on physical performance among U-14 young soccer players. J. Strength Cond. Res. 24, 644-652. doi: 10.1519/JSC.0b013e3181ad3349

Conflict of Interest Statement: The authors declare that the research was conducted in the absence of any commercial or financial relationships that could be construed as a potential conflict of interest.

Copyright (c) 2017 Behm, Young, Whitten, Reid, Quigley, Low, Li, Lima, Hodgson, Chaouachi, Prieske and Granacher. This is an open-access article distributed under the terms of the Creative Commons Attribution License (CC BY). The use, distribution or reproduction in other forums is permitted, provided the original author(s) or licensor are credited and that the original publication in this journal is cited, in accordance with accepted academic practice. No use, distribution or reproduction is permitted which does not comply with these terms. 